ARTICLE

Received 18 Feb 2015 | Accepted 23 Jul 2015 | Published 18 Sep 2015

DOI: $10.1038 /$ ncomms9136

OPEN

\title{
The seasonal sea-ice zone in the glacial Southern Ocean as a carbon sink
}

\author{
Andrea Abelmann ${ }^{1}$, Rainer Gersonde ${ }^{1}$, Gregor Knorr ${ }^{1}{ }^{1}$, Xu Zhang $^{1}$, Bernhard Chapligin ${ }^{1}$, Edith Maier ${ }^{1}$, \\ Oliver Esper', Hans Friedrichsen ${ }^{3}$, Gerrit Lohmann', Hanno Meyer ${ }^{1} \&$ Ralf Tiedemann ${ }^{1}$
}

Reduced surface-deep ocean exchange and enhanced nutrient consumption by phytoplankton in the Southern Ocean have been linked to lower glacial atmospheric $\mathrm{CO}_{2}$. However, identification of the biological and physical conditions involved and the related processes remains incomplete. Here we specify Southern Ocean surface-subsurface contrasts using a new tool, the combined oxygen and silicon isotope measurement of diatom and radiolarian opal, in combination with numerical simulations. Our data do not indicate a permanent glacial halocline related to melt water from icebergs. Corroborated by numerical simulations, we find that glacial surface stratification was variable and linked to seasonal sea-ice changes. During glacial spring-summer, the mixed layer was relatively shallow, while deeper mixing occurred during fall-winter, allowing for surface-ocean refueling with nutrients from the deep reservoir, which was potentially richer in nutrients than today. This generated specific carbon and opal export regimes turning the glacial seasonal sea-ice zone into a carbon sink.

\footnotetext{
${ }^{1}$ Alfred Wegener Institute Helmholtz Centre for Polar and Marine Research, Am Alten Hafen 26, Bremerhaven 27568, Germany. ${ }^{2}$ Cardiff School of Earth and Ocean Sciences, Cardiff, Wales CF10 3AT, UK. ${ }^{3}$ Free University of Berlin, Berlin 14195, Germany. Correspondence and requests for materials should be addressed to A.A. (email: Andrea.Abelmann@awi.de).
} 
T he past four climate cycles are characterized by a repetitive pattern of gradually declining and rapidly increasing atmospheric $\mathrm{CO}_{2}$ concentrations, ranging between $\sim 180$ p.p.m. during glacials and $\sim 280$ p.p.m. during interglacials ${ }^{1}$. Although multiple processes on land and in the ocean are involved in the modulation of the observed $\mathrm{CO}_{2}$ variability ${ }^{2}$, physical and biological processes in the Southern Ocean (SO) have been identified to be the key in these changes ${ }^{3}$. This view is supported by the tight relationship between $\mathrm{CO}_{2}$ and Antarctic temperature development ${ }^{4}$. Most important are changes in ocean ventilation/stratification, sea-ice extent, wind patterns, atmospheric transport of micronutrients (for example, iron) and biological productivity and export, according to proxy and model-based studies ${ }^{3,5-11}$. Despite the scientific progress, the different hypotheses on the SO's sensitivity to modulate the carbon cycle and the identification of involved processes remain under debate. In the SO, the availability of silicon nutrients $(\mathrm{Si})$, the consumption by primary producers (diatoms) and cycling pathways are key for effective carbon sequestration ${ }^{8,12}$. The widespread deposition of biogenic opal, which consists primarily in diatoms but also in radiolarians and, to a minor extent, in sponge spicules, allows for the application of specific opal-based proxies to trace these processes and related environmental conditions. However, controversial views exist for the interpretation of the proxies used to trace past productivity and their impact on the carbon cycle ${ }^{3,5,13}$. Similarly, glacialinterglacial changes in surface ocean stratification, which control ocean atmosphere exchange and the availability of nutrients, have been discussed contentiously. This has resulted in different notions of the impact of physical and biological processes in ice-free and ice-covered areas on the glacial-interglacial climate evolution ${ }^{3,5,13}$. Isotope records of diatom-bound nitrogen $\left(\delta^{15} \mathrm{~N}\right)$ are interpreted to indicate a low-productivity glacial seasonal sea-ice zone (SIZ) resulting from constricted nutrient supply to the surface ocean, owing to permanent and enhanced nearsurface stratification ${ }^{3,13}$. Further information on surface water (euphotic zone) conditions comes from oxygen isotopes $\left(\delta^{18} \mathrm{O}\right)$ of diatoms, used to identify meltwater supply from the Antarctic continent ${ }^{14-17}$. Silicon isotope $\left(\delta^{30} \mathrm{Si}\right)$ measurements on diatoms and sponge spicules provide insights into the development of silicon utilization in surface waters ${ }^{9-20}$ and the silicon inventory of the deep ocean ${ }^{19,21,22}$. A yet unexploited window into subsurface and deeper water conditions presents the isotope signal from radiolarians (protozooplankton). In combination with the diatom isotope data, these signals provide an enhanced framework to detect changes of upper and lower water column conditions, and thus the pattern and glacial-interglacial variability of stratification and nutrient exchange.

Here we apply the new approach to combine $\delta^{18} \mathrm{O}$ and $\delta^{30} \mathrm{Si}$ measurements of diatom and radiolarian opal to two late Quaternary sediment cores (PS1768-8 and PS1778-5) from the sea ice-free Antarctic Zone and from the Polar Front Zone of the Atlantic sector of the SO, respectively (Fig. 1). We are aware that the calibration of the new proxies requires further investigations, especially with respect to the isotope fractionation of radiolarians. Here we attenuate the lack of data on radiolarian fractionation by combining $\delta^{30} \mathrm{Si}$ measurements from surface sediments and water-column samples available from the study area. As least information is available on oxygen isotope fractionation of radiolarians, we primarily base our $\delta^{18} \mathrm{O}$-related interpretations on the signals from diatom opal. Altogether, the combination of our opal isotope results with other proxy data and climate simulations using a fully coupled global atmosphere-ocean general circulation model ${ }^{23}$ (AOGCM) enables the establishment of coherent paleoceanographic scenarios. This combined data/ modelling interpretation implies that the glacial near-surface

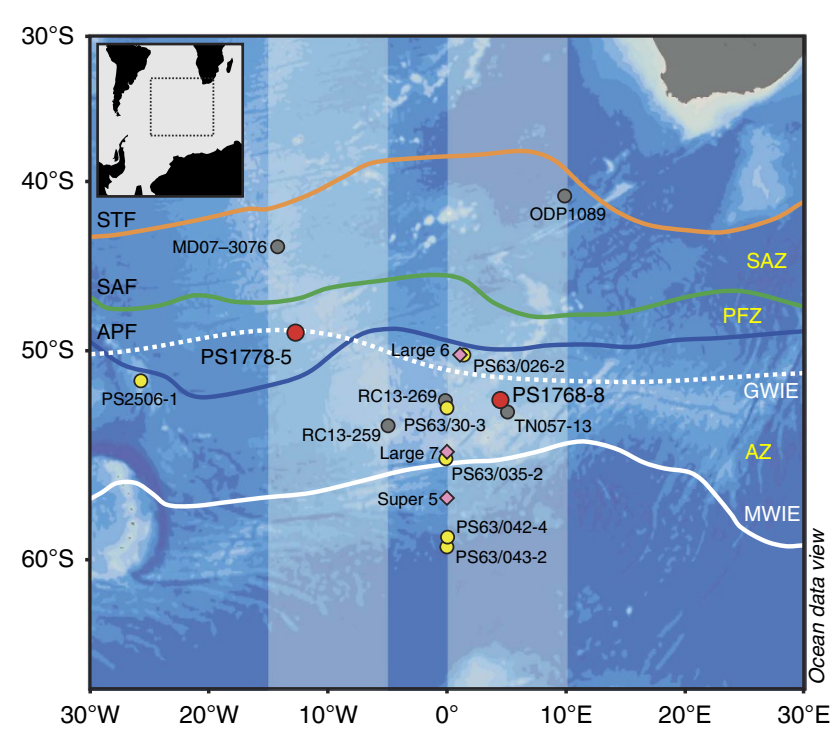

Figure 1 | Map of the study area. The map shows the location of sediment core PS1768-8 in the sea-ice free Antarctic Zone (AZ) of the Atlantic sector of the Southern Ocean and core PS1778-5 from the Polar Front Zone (PFZ). Also indicated are sites of water column sampling ${ }^{29}$ (pink diamonds), surface sediment sampling (yellow dots), and locations of cores discussed in the text (grey dots). Locations of the modern winter ice edge (MWIE) and the GWIE were derived from data in refs 34,67, respectively. Oceanic fronts from ref. 68: Antarctic Polar Front (APF), Subantarctic Front (SAF) and Subtropical Front (STF); the latter two delimit the Subantarctic Zone (SAZ). Light-blue-shaded areas represent the zones of modelled transects (Fig. 5b-e).

stratification in the SIZ was variable. Relatively deep mixing during fall and winter allowed for surface-ocean refueling with nutrients from a potentially enriched deep reservoir, which generated a carbon sink in the glacial SIZ.

\section{Results}

Opal-based isotope proxies. A critical requirement for appropriate analyses and interpretation of $\delta^{18} \mathrm{O}$ and $\delta^{30} \mathrm{Si}$ in diatom $\left(\delta^{18} \mathrm{O}_{\text {diat }}\right.$ and $\left.\delta^{30} \mathrm{Si}_{\text {diat }}\right)$ and radiolarian $\left(\delta^{18} \mathrm{O}_{\text {rad }}\right.$ and $\left.\delta^{30} \mathrm{Si}_{\text {rad }}\right)$ opal is the extraction and separation of both microfossil groups (Methods, Supplementary Figs 1-4 and Supplementary Table 1). Our diatom fraction $(10-40 \mu \mathrm{m})$ used for isotope measurements to reconstruct surface water conditions is dominated by two species: Eucampia antarctica in the lower part of the cores and Thalassiosira lentiginosa in the upper core portions. The shift in species composition is abrupt and its timing is unrelated to the glacial-interglacial change of the opal isotope signals (Methods and Supplementary Fig. 5), which suggests that the diatom isotope signals are not biased by species-related effects. Except for two studies from the North Pacific, this is in line with other investigations, indicating vital effects to be either non-existent or within the analytical reproducibility ${ }^{14,17,24}$. In contrast to the diatoms, the species composition of the individual radiolarian fractions does not significantly vary throughout the investigated core sections, so that species-related isotope effects in the different fractions remain unlikely. The radiolarian fraction $>250 \mu \mathrm{m}$ (PS1768-8) consists of two large-sized species (Actinomma antarctica and Spongotrochus glacialis adult), mainly dwelling in the upper $100-400 \mathrm{~m}$ of the water column, thus representing surface-subsurface conditions (Supplementary Table 2). Radiolarians assembled in the 125- to $250-\mu \mathrm{m}$ fraction (PS1768-8) and the $>125-\mu \mathrm{m}$ fraction (PS1778-5) display a more diverse species composition, also including species with a deeper 
habitat ( $>400 \mathrm{~m})^{25}$ (Methods). We also rule out seasonal effects, because sediment trap studies show that the diatom and radiolarian export in the SIZ of the SO occur synchronously and are restricted to spring-summer ${ }^{26}$.

The $\delta^{18} \mathrm{O}$ signal in diatoms generally depends on both temperature and $\delta^{18} \mathrm{O}$ in seawater ${ }^{17}$. A robust relationship between diatom $\delta^{30} \mathrm{Si}$ and silicic acid utilization is derived from culture experiments and field data ${ }^{19,20,24,27-30}$. Diatom culture studies point to a mean fractionation factor of $-1.1 \%$ (ref. 24) and show limited variation with species and growth rate ${ }^{19}$. Larger variability in diatom $\delta^{30} \mathrm{Si}$ fractionation was derived from field data ranging between approximately $-0.6 \%$ and $-2.3 \%$, which reflects the natural variation but also the methodological challenge of calculating fractionation offsets ${ }^{19}$ (Fig. 2b). Although the oxygen and silicon isotope fractionation of diatoms is rather well investigated, the knowledge concerning the isotope fractionation of radiolarians is less developed. The generation of such data is complicated by the lack of successful radiolarian culturing experiment ${ }^{31}$ and isotope measurements of radiolarians collected in the water column. A first approach to obtain information on this important issue relies on the modelling of a fractionation offset ranging between $-1.1 \%$ and $-2.1 \%$ derived from deglacial $\delta^{30} \mathrm{Si}_{\text {rad }}$ values ${ }^{32}$. To assist the interpretation of our results, we moved a step forward and estimated the radiolarian fractionation offset $\left(\Delta \delta^{30} \mathrm{Si}_{\mathrm{rad}}\right)$ by using $\delta^{30} \mathrm{Si}_{\text {rad }}$ values from four surface sediment samples from the Atlantic sector in combination with $\delta^{30} \mathrm{Si}_{\mathrm{Si}(\mathrm{OH}) 4}$ values from surface and deeper waters close to the surface sediment sample sites $^{29}$ (Figs 1,2a,b, and Supplementary Table 3). Considering that the fractionation of diatoms and sponges is suggested to occur in equilibrium with the surrounding water ${ }^{19,24}$, it is reasonable to assume that this is also true for the fractionation of radiolarians. For the calculation of $\Delta \delta^{30} \mathrm{Si}_{\text {rad }}$, we used the following equation adapted from ref. 21

$$
\varepsilon \sim \Delta \delta^{30} \mathrm{Si}_{\text {rad }}=\delta^{30} \mathrm{Si}_{\text {rad }}-\delta^{30} \mathrm{Si}_{\mathrm{Si}(\mathrm{OH}) 4}
$$

where $\varepsilon$ is the fractionation factor by opal-producing organisms, $\delta^{30} \mathrm{Si}_{\text {rad }}$ is the silicon isotope composition of radiolarian opal and $\delta^{30} \mathrm{Si}_{\mathrm{Si}(\mathrm{OH}) 4}$ is the silicon isotope composition of sea water. The $\Delta \delta^{30} \mathrm{Si}_{\text {rad }}$ values were calculated with $\delta^{30} \mathrm{Si}_{\mathrm{Si}(\mathrm{OH}) 4}$ values averaged from two different water depth intervals ( 0 to $\sim 300-400 \mathrm{~m}$ and 0 to $\sim 1,000 \mathrm{~m}$ ), to cover all possible depth ranges of the included species (Fig. 2b and Supplementary Table 3). The obtained $\Delta \delta^{30} \mathrm{Si}_{\text {rad }}$ values range between $-0.5 \%$ and $-0.9 \%$, and show a linear relationship with the $\mathrm{Si}(\mathrm{OH})_{4}$ concentrations. The $\delta^{30} \mathrm{Si}_{\text {rad }}$ fractionation offset calculated in our study is more positive than the fractionation applied in ref. $32(-1.1 \%$ to $-2.1 \%$ ). However, both fractionation estimates are in the range of the observed diatom fractionation (Fig. 2b). The modern $\delta^{30} \mathrm{Si}_{\text {rad }}$ values display an inverse trend to the $\mathrm{Si}(\mathrm{OH})_{4}$ concentrations $\mathrm{s}^{29,33}$ in the upper 400 and upper $1,000 \mathrm{~m}$ of the water column (Fig. 2a and Supplementary Table 3). Higher $\delta^{30} \mathrm{Si}_{\text {rad }}$ values of approximately $+1.4 \%$ correspond to lower $\mathrm{Si}(\mathrm{OH})_{4}$ concentrations of $30-45 \mu \mathrm{Ml}^{-1}$, whereas lower $\delta^{30} \mathrm{Si}_{\text {rad }}$ values of $+0.7 \%$ and $+0.8 \%$ correlate with higher $\mathrm{Si}(\mathrm{OH})_{4}$ concentrations of $67-98 \mu \mathrm{Ml}^{-1}$, which is comparable to the relationship between $\delta^{30} \mathrm{Si}$ values and $\mathrm{Si}(\mathrm{OH})_{4}$ concentrations documented for diatoms and sponges.

To test the reliability of the available information on diatom and radiolarian fractionation we calculated $\delta^{30} \mathrm{Si}_{\mathrm{Si}(\mathrm{OH}) 4}$ from ${ }^{30} \mathrm{Si}$ values of radiolarians and diatoms averaged over the Holocene in both cores (Methods and Supplementary Table 4) and related the obtained $\left.\delta^{30} \mathrm{Si}_{\mathrm{Si}} \mathrm{OH}\right) 4$ data to $\delta^{30} \mathrm{Si}_{\mathrm{Si}(\mathrm{OH}) 4}$ and $\mathrm{Si}(\mathrm{OH})_{4}$ concentrations reported from modern water column studies ${ }^{29}$ (Fig. 3a). In our $\delta^{30} \mathrm{Si}_{\mathrm{Si}}(\mathrm{OH}) 4$ calculation we considered a fractionation of $-1.1 \%$ for diatom $\delta^{30} \mathrm{Si}$ data ${ }^{24}$. Considering the
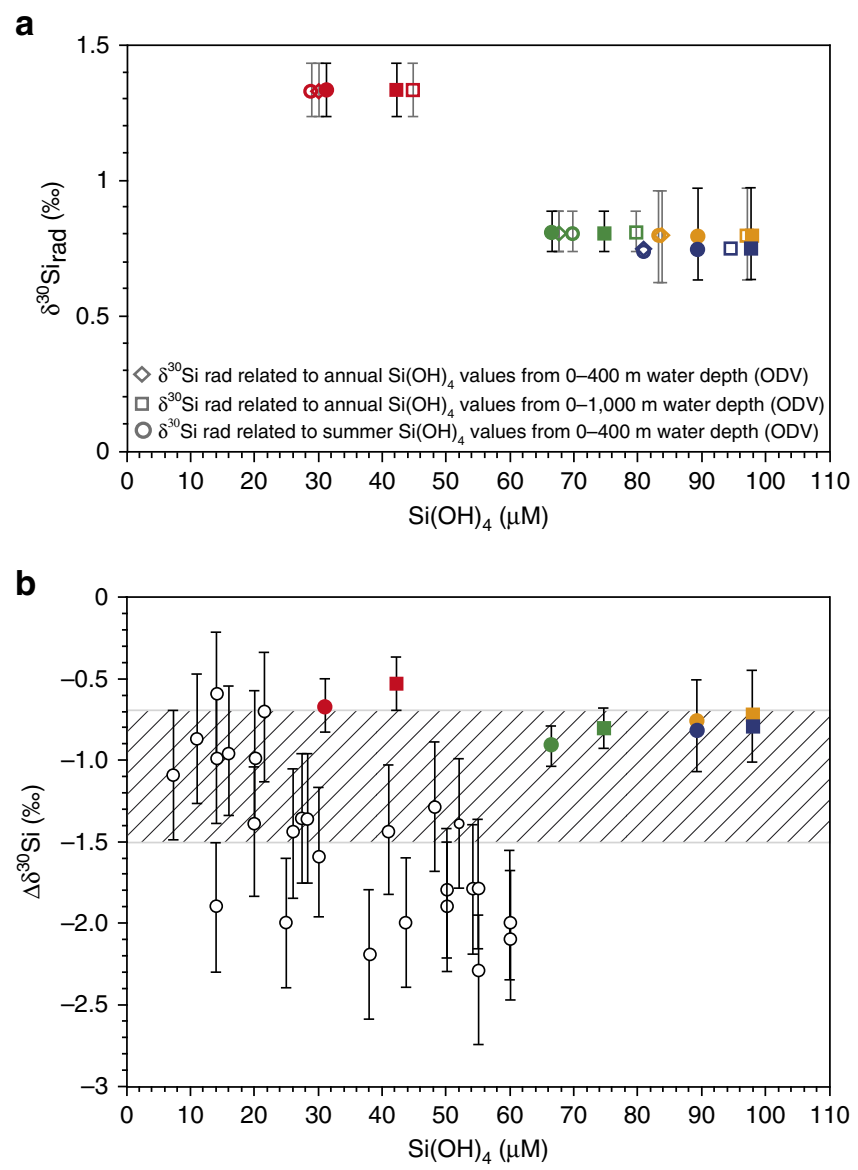

Figure $2 \mid \delta^{30} \mathrm{Si}$ data of radiolarians $\left(\delta^{30} \mathrm{Si}_{\mathrm{rad}}\right)$ and $\Delta \delta^{30} \mathrm{Si}$ offsets in surface sediments compared with $\mathrm{Si}(\mathrm{OH})_{4}$ concentrations and to $\Delta \delta^{30} \mathrm{Si}$ offsets of diatoms. (a) $\delta^{30} \mathrm{Si}$ data of radiolarians $\left(\delta^{30} \mathrm{Si}_{\text {rad }}\right)$ in four surface sediments from the study area compared with $\mathrm{Si}(\mathrm{OH})_{4}$ concentrations in sea water. Colours refer to different surface sediments (red: PS63/026-2, green: PS63/035-2, blue: PS63/042-2, orange: PS63/043-2) (for site location, see Fig. 1 and Supplementary Table 3). Filled circles and squares present the $\delta^{30} \mathrm{Si}_{\text {rad }}$ values (Supplementary Table 3) plotted versus $\mathrm{Si}(\mathrm{OH})_{4}$ concentrations measured at different water depth intervals (filled circles: upper 300-400 m and filled squares: upper 1,000 m) at nearby seawater sampling stations ${ }^{29}$ (Fig. 1 and Supplementary Table 3), whereas the open symbols display the $\delta^{30} \mathrm{Si}_{\text {rad }}$ values plotted versus annual and summer $\mathrm{Si}(\mathrm{OH})_{4}$ concentrations at different water depth intervals in the study area according to the World Ocean Atlas ${ }^{33}$ (Supplementary Table 3). (b) $\Delta \delta^{30} \mathrm{Si}$ offsets between $\delta^{30} \mathrm{Si}$ values of seawater samples ${ }^{27-29,69}$ and $\delta^{30} \mathrm{Si}$ values of radiolarians $\left(\delta^{30} \mathrm{Si}_{\text {rad }}\right)$ and diatoms $\left(\delta^{30} \mathrm{Si}_{\text {diat }}\right)$, respectively, versus seawater $\mathrm{Si}(\mathrm{OH})_{4}$ concentrations at the seawater sampling stations. Coloured symbols display different surface sediments (see Fig. 2a). Different symbols (circles and squares) display the $\Delta \delta^{30}$ Si offsets between $\delta^{30} \mathrm{Si}_{\text {rad }}$ values of the four surface sediment samples and seawater $\delta^{30} \mathrm{Si}$ values at different water depth intervals (filled circles: upper $\sim 300-400 \mathrm{~m}$ and filled squares: upper $1,000 \mathrm{~m}$, see Fig. 2a) at the nearby oceanographic stations ${ }^{29}$ The dashed area illustrates the diatom $\delta^{30} \mathrm{Si}$ fractionation offset of $-1.1 \pm 0.4 \%$ obtained from diatom culture studies ${ }^{24}$. The white dots with error bars display the $\Delta \delta^{30} \mathrm{Si}$ offsets between $\delta^{30} \mathrm{Si}_{\text {diat }}$ and $\delta^{30} \mathrm{Si}$ of seawater obtained from field data $27-29,69$. Error bars show $\pm 2 \sigma$ s.d.

remaining uncertainty in the definition of radiolarian fractionation offsets, we tested the applicability of three offset values. This includes $\Delta \delta^{30} \mathrm{Si}_{\text {rad }}$ of $-0.8 \%$ (average estimated offset from this study, Supplementary Tables 3 and 4 ), $-1.5 \%$ (average estimated offset from ref. 32) and $-1.2 \%$ representing an average over both. We note that the Holocene $\delta^{30} \mathrm{Si}_{\mathrm{Si}(\mathrm{OH}) 4}$ 
a

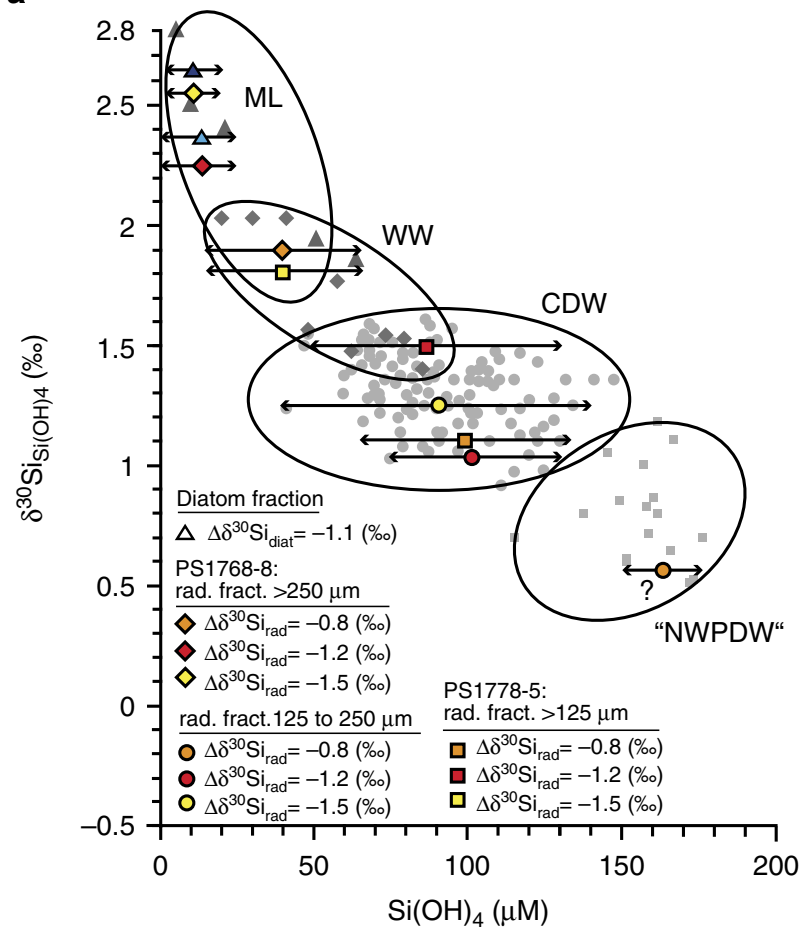

b

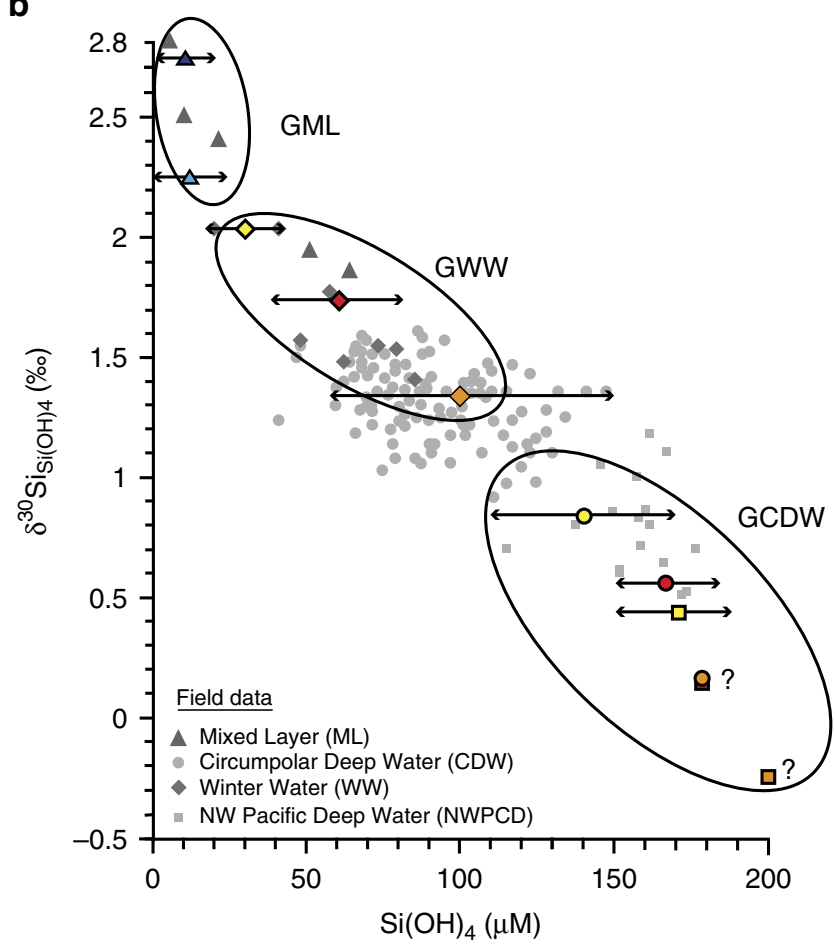

Figure 3 | Reconstructed $\delta^{30} \mathrm{Si}_{\mathrm{Si}(\mathrm{OH} 4)}$ values and $\mathrm{Si}(\mathrm{OH})_{4}$ seawater concentrations compared with values in modern water masses.

(a) Average Holocene and (b) glacial-time $\delta^{30} \mathrm{Si}_{\mathrm{si}}(\mathrm{OH} 4)$ values and $\mathrm{Si}(\mathrm{OH})_{4}$ concentrations in seawater reconstructed from $\delta^{30} \mathrm{Si}_{\text {rad }}$ data and $\delta^{30} \mathrm{Si}_{\text {diat }}$ values in cores PS1768-8 and PS1778-5 compared with modern seawater $\delta^{30} \mathrm{Si}_{\mathrm{si}(\mathrm{OH} 4)}$ values and $\mathrm{Si}(\mathrm{OH})_{4}$ concentrations in different water masses ${ }^{29}$ (Supplementary Table 4). The blue triangles indicate the $\delta^{30} \mathrm{Si}_{\mathrm{Si}}(\mathrm{OH} 4)$ values reconstructed from the $\delta^{30} \mathrm{Si}_{\text {diat }}$ data of the two cores by using a $\Delta \delta^{30} \mathrm{Si}$ offset of $-1.1 \%$ (light blue: core PS1768-8 and dark blue: core PS1778-5), the coloured diamonds indicate the ${ }^{30} \mathrm{Si}_{\mathrm{Si}(\mathrm{OH} 4)}$ values reconstructed from the $\delta^{30} \mathrm{Si}_{\mathrm{rad}}$ data of the size fraction $>250 \mu \mathrm{m}$ in core PS1768-8, the coloured dots indicate the $\delta^{30} \mathrm{Si}_{\mathrm{Si}(\mathrm{OH} 4)}$ values reconstructed from the $\delta^{30} \mathrm{Si}_{\text {rad }}$ data of the size fraction $125-250 \mu \mathrm{m}$ in core PS1768-8 and the coloured squares indicate the ${ }^{30}{ }^{\left.3 \mathrm{Si}_{\mathrm{Si}} \mathrm{OH} 4\right)}$ values reconstructed from the $\delta^{30} \mathrm{Si}_{\text {rad }}$ data of the size fraction $>125 \mu \mathrm{m}$ in core PS1778-5. The $\Delta \delta^{30} \mathrm{Si}$ offsets applied to the $\delta^{30} \mathrm{Si}_{\mathrm{rad}}$ data were $-0.8 \%$ (orange), $-1.2 \%$ (red) and $-1.5 \%$ (yellow) (see Methods). The obtained $\delta^{30} \mathrm{Si}_{\mathrm{i}(\mathrm{OH}) 4}$ values were related to $\delta^{30} \mathrm{Si}_{\mathrm{i}(\mathrm{OH}) 4}$ values from water stations and to their ranges in $\mathrm{Si}(\mathrm{OH})_{4}$ concentrations $\mathrm{s}^{20,28,29}$. The modern $\delta^{30} \mathrm{Si}$ values and $\mathrm{Si}(\mathrm{OH})_{4}$ concentrations were measured on seawater samples from the mixed layer $(\mathrm{ML} \text {; grey triangles) })^{29}$, Winter Water (WW; grey diamonds) ${ }^{29}, \mathrm{CDW}$ (grey dots) ${ }^{28,29}$ and Northwest Pacific Deep Water ('NWPDW'; grey squares) ${ }^{20}$. The reconstructed glacial-time $\delta^{30} \mathrm{Si}_{\mathrm{si}(\mathrm{OH} 4)}$ values and $\mathrm{Si}(\mathrm{OH})_{4}$ concentrations (b) may allow to discriminate Glacial Mixed Layer (GML), Glacial WW (GWW) and Glacial CDW (GCDW). Double-headed arrows display the range in $\mathrm{Si}(\mathrm{OH})_{4}$ concentrations that can be attributed to the reconstructed $\left.\delta^{30} \mathrm{Si}_{\mathrm{si}} \mathrm{OH} 4\right)$ values. It is worth noting that $\delta^{30} \mathrm{Si}_{\mathrm{Si}}(\mathrm{OH} 4)$ estimations based on $\Delta \delta^{30} \mathrm{Si}_{\text {rad }}$ of $-0.8 \%$ may tend to overestimated $\mathrm{Si}(\mathrm{OH})_{4}$ concentrations.

values reconstructed from $\delta^{30} \mathrm{Si}$ of diatoms and surfacesubsurface dwelling radiolarians ( $>250 \mu \mathrm{m}$ fraction) are in the range of $\delta^{30} \mathrm{Si}_{\mathrm{Si}(\mathrm{OH}) 4}$ values reported from the modern mixed layer (ML) in the Atlantic sector of the $\mathrm{SO}^{29}$ (Fig. 3a). The ${ }^{30} \mathrm{Si}_{\mathrm{Si}(\mathrm{OH}) 4}$ values reconstructed from the $\delta^{30} \mathrm{Si}$ data in the radiolarian fractions $125-250 \mu \mathrm{m}$ and $>125 \mu \mathrm{m}$, which also include species with a deeper habitat, are shifted towards lower values. These $\delta^{30} \mathrm{Si}_{\mathrm{Si}(\mathrm{OH}) 4}$ values are in the range of $\delta^{30} \mathrm{Si}_{\mathrm{Si}(\mathrm{OH}) 4}$ data and $\mathrm{Si}(\mathrm{OH})_{4}$ concentrations from the Circumpolar Deep Water $(\mathrm{CDW})^{28,29}$ (Fig. 3a). While the application of $\Delta \delta^{30} \mathrm{Si}_{\mathrm{rad}}$ values of $-1.2 \%$ and $-1.5 \%$ leads to realistic seawater $\mathrm{Si}(\mathrm{OH})_{4}$ concentrations, estimates calculated with a fractionation offset of $-0.8 \%$ tend to result in overestimated $\mathrm{Si}(\mathrm{OH})_{4}$ concentration. This is most apparent for the result from the $125-$ to $250-\mu \mathrm{m}$ radiolarian fraction (PS1768-8) reaching values comparable to those in modern Northwest Pacific Deep Water ${ }^{20}$, which exceed $\mathrm{CDW}$ concentrations (Fig. 3a). Although information on isotope fractionation in radiolarians remains incomplete and requires additional efforts (for example, in water column studies and new approaches for radiolarian culturing), our $\Delta \delta^{30} \mathrm{Si}_{\text {rad }}$ calculations and their relation to modern $\mathrm{Si}(\mathrm{OH})_{4}$ concentrations point to a similar fractionation in diatoms and radiolarians. This assumption represents a step towards quantification of past
$\mathrm{Si}(\mathrm{OH})_{4}$ concentration and its variability in surface and subsurface to intermediate-deeper water.

Down-core data interpretation. During the last glacial, core PS1768-8 $\left(52^{\circ} 35.61^{\prime} \mathrm{S}, 4^{\circ} 28.5^{\prime} \mathrm{E}\right.$, water depth $\left.3,270 \mathrm{~m}\right)$ was positioned in the northern glacial SIZ and core site PS1778-5 $\left(49^{\circ} 00.7^{\prime} \mathrm{S}, 12^{\circ} 41.8^{\prime} \mathrm{W}\right.$, water depth $\left.3,380 \mathrm{~m}\right)$ was in the area of the glacial winter sea-ice edge (GWIE) ${ }^{34}$ (Fig. 1 and Supplementary Fig. 6). This is in agreement with glacial-time winter sea-ice concentrations (WSICs) based on a new transfer function ${ }^{35}$, which display glacial sea-ice concentrations $\sim 60 \%$ in the PS1768-8 record (Fig. $4 \mathrm{e}$ ) and $\sim 40 \%$ at PS1778-5 (Fig. $4 \mathrm{i}$ ). We assigned sea-ice concentrations of $40 \%-50 \%$ to be indicative of the average paleo-sea-ice edge, because these values are in the middle of the abrupt decline of Antarctic sea-ice concentration, which marks the modern sea-ice edge ${ }^{35,36}$. A similar definition of the average sea-ice edge was proposed based on microwave remote-sensing observations ${ }^{37}$. Our sediments document the last glacial, the glacial-interglacial transition and the early part of the Holocene (Fig. 4). In the absence of biogenic carbonate, which hampers the development of continuous foraminiferal oxygen isotope records and carbonate-based $\mathrm{AMS}^{14} \mathrm{C}$ data series in the studied cores, the generation of age models for both cores 
considers the dating strategy and stratigraphic data from a compilation of last glacial sea-surface temperature and sea-ice records from the Atlantic sector of the $\mathrm{SO}^{38}$ (Methods and Supplementary Figs 7,8).

In both cores, PS1768-8 and PS1778-5, the $\delta^{18} \mathrm{O}_{\text {diat }}$ and $\delta^{18} \mathrm{O}_{\text {rad }}$ signals display a similar pattern with decreasing values

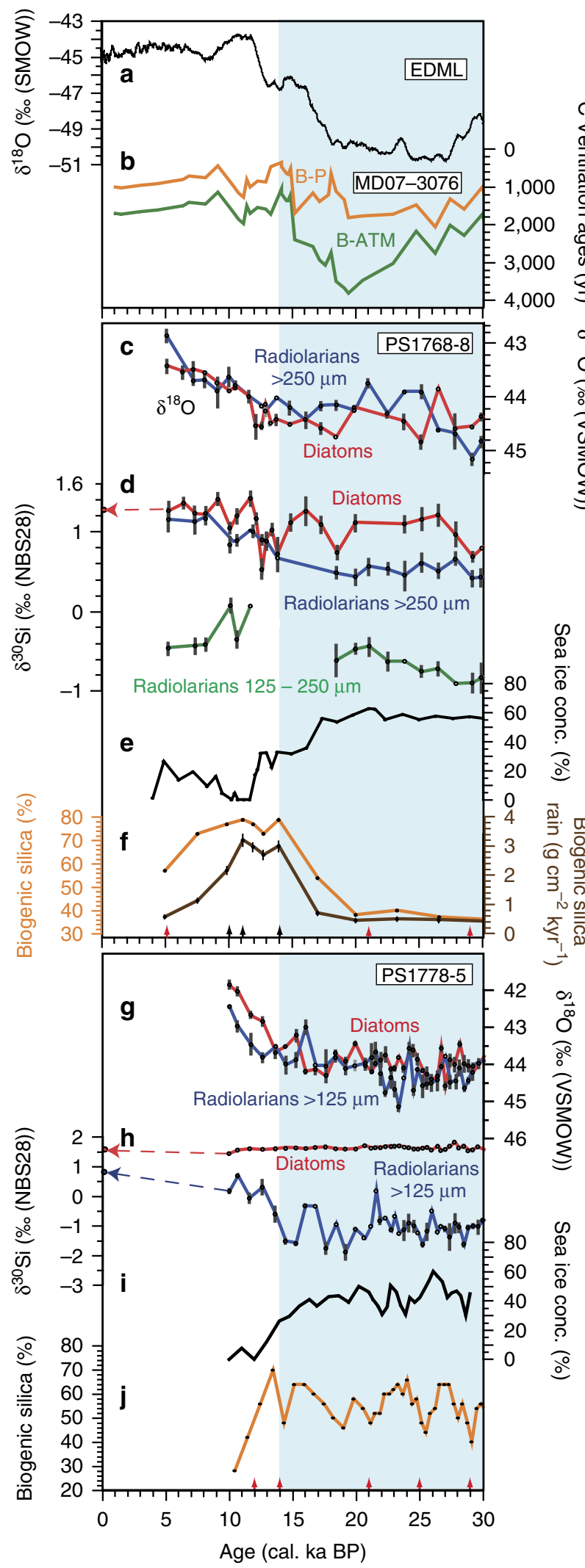

from the last glacial period to the early Holocene (Fig. 4c,g). The $\delta^{18} \mathrm{O}_{\text {diat }}$ and $\delta^{18} \mathrm{O}_{\text {rad }}$ values range between $+45.1 \%$ and $+41.7 \%$, thus being close to the $\delta^{98} \mathrm{O}_{\text {diat }}$ values obtained from other SO sediment cores ${ }^{14-16}$. The major shifts from glacial to Holocene $\delta^{18} \mathrm{O}$ values occur in close relation to sea-surface water temperature (SST) increase overprinting the ice volume signal (Supplementary Figs 7 and 8). The early-middle Holocene diatom and radiolarian $\delta^{18} \mathrm{O}$ records from PS1768-8 display a trend similar to a planktic foraminifer $\delta^{18} \mathrm{O}$ record from the nearby core TN057-13 (ref. 15, Fig. 1 and Supplementary Fig. 7). At both sites, our $\delta^{18} \mathrm{O}_{\text {diat }}$ records are inconsistent with distinct glacial freshwater supply resulting from iceberg melting. This differs from the $\delta^{18} \mathrm{O}_{\text {diat }}$ records reported from cores TN057-13 (ref. 15) and RC13-259 (ref. 14) recovered in our study area (Fig. 1). These records are characterized by generally lower glacial values and higher $\delta^{18} \mathrm{O}_{\text {diat }}$ values during the last deglaciation and the Holocene. In TN057-13, the $\delta^{18} \mathrm{O}_{\text {diat }}$ record is punctuated by $\delta^{18} \mathrm{O}_{\text {diat }}$ decreases that are in close correlation with increased values of ice rafted debris (IRD $)^{15}$. According to a more recent geochemical study, IRD in TN057-13 primarily consists of volcanic tephra from the South Sandwich Islands transported by sea ice to the studied site ${ }^{39}$. Measurements of $\delta^{18} \mathrm{O}$ on samples that contain, besides biogenic silica, also non-biogenic components such as terrigenous minerals and volcanic tephra, may result in lower $\delta^{18} \mathrm{O}$ values and thus bias the isotopic signal towards freshwater-related values ${ }^{17,40}$. Therefore, the apparent anti-correlation between the content of IRD (mostly tephra) and $\delta^{18} \mathrm{O}_{\text {diat }}$ values in core TN057-13 may not only be explained by salinity decrease due to iceberg melting but also by a contribution from $\delta^{18} \mathrm{O}$-depleted tephra to the $\delta^{18} \mathrm{O}_{\text {diat }}$ signal. In contrast, IRD deposition in core PS1768-8 decreases between 18 and 16 cal. ka BP. Thus, the $\delta^{18} \mathrm{O}_{\text {diat }}$ values show no correlation with IRD (Supplementary Fig.7), which suggests that the $\delta^{18} \mathrm{O}_{\text {diat }}$ data presented here may be more reliable than those of ref. 15. This is confirmed by the purity of the cleaned samples in this study, which is exceptionally high, ranging between $97.9 \%$ and $99.8 \%$ $\mathrm{SiO}_{2}$ (Methods and Supplementary Table 1), ruling out bias of our $\delta^{18} \mathrm{O}_{\text {diat }}$ values.

Figure 4 | Oxygen and silicon isotope records of diatoms and radiolarians from cores PS1768-8 and PS1778-5 compared with other paleoclimatic records over the last 30 kyr. (a) $\delta^{18} \mathrm{O}$ record of Antarctic ice core drilled at EPICA Dronning Maud Land (EDML) site ${ }^{70}$ against AICC2012 (Antarctic Ice Core Chronology 2012) ${ }^{62}$. (b) ${ }^{14} \mathrm{C}$ ventilation ages plotted as benthic-planktic foraminifera age difference (B-P) and benthicatmospheric difference (B-ATM) from core MD07-3076 (Fig. 1) ${ }^{57}$. (c-f) Proxies from core PS1768-8 located in the glacial SIZ. (c) $\delta^{18} \mathrm{O}$ and (d) $\delta^{30} \mathrm{Si}$ records from one diatom and two radiolarian fractions ( $>250 \mu \mathrm{m}$ and $125-250 \mu \mathrm{m}$ ) measured at the same aliquot of biogenic opal. The red dashed arrow points to the $\delta^{30} \mathrm{Si}_{\text {diat }}$ value obtained from a nearby seafloor surface-sediment sample assumed to be of modern age (Supplementary Table 7). Error bars indicate range of replicate and triplicate measurements (Supplementary Tables 8-12). (e) Diatom transfer function-based estimates of WSIC ${ }^{35}$. (f) Biogenic silica percentages and biogenic silica rain rates 50 . (g-j) Proxies from core PS1778-5 located close to the GWIE. (g) $\delta^{18} \mathrm{O}$ and (h) $\delta^{30}$ Si records of diatoms and radiolarians ( $>125 \mu \mathrm{m}$ fraction) measured at the same aliquot of biogenic opal. The red and blue dashed arrows point to the $\delta^{30} \mathrm{Si}_{\text {diat }}$ and $\delta^{30} \mathrm{Si}_{\text {rad }}$ values obtained from a nearby seafloor surface sediment sample assumed to be of modern age (Supplementary Table 7) (i) Diatom transfer function-based estimates of WSIC. (j) Biogenic silica percentages. Arrows in $\mathbf{f}$ and $\mathbf{j}$ indicate age pointers (black arrows mark $\mathrm{AMS}^{14} \mathrm{C}$ dates and red arrows mark ages obtained by diatom and radiolarian biofluctuation stratigraphy, see Supplementary Tables 5 and 6). Blue-shaded area delineates Marine Isotope Stage (MIS) 2 and the late part of MIS 3. 
The $\delta^{30} \mathrm{Si}$ signal of diatoms in core PS1768-8 ranges generally around $+1 \%$ in the glacial and increases to about $+1.2 \%$ in the Holocene (Fig. 4d). The values correspond well to those reported from the nearby core RC13-269 (ref. 41 and Fig. 1). In the northern core PS1778-5, we observe distinctly higher glacial $\delta^{30} \mathrm{Si}_{\text {diat }}$ values around $+1.6 \%$ and a slight decrease by $\sim 0.05 \%$ towards the Holocene, which is however within the analytical error (Fig. 4h).

In comparison with the diatom records, the contrasts between glacial and interglacial $\delta^{30} \mathrm{Si}_{\text {rad }}$ values are generally more pronounced. During glacial conditions, the silicon isotope signals of diatoms and radiolarians in core PS1768-8 display offsets, with $\sim 0.6 \%$ lower $\delta^{30} \mathrm{Si}_{\text {rad }}$ values in the $>250 \mu \mathrm{m}$ fraction that represents surface-subsurface conditions and $\sim 1.7 \%$ lower $\delta^{30} \mathrm{Si}_{\text {rad }}$ values in the $125-$ to $250-\mu \mathrm{m}$ fraction, which also includes signals from intermediate-deeper waters. Even more pronounced is the offset between the glacial diatom and radiolarian $\delta^{30} \mathrm{Si}$ signals from the northern core PS1778-5 where the radiolarian fraction $>125 \mu \mathrm{m}$ combines species dwelling at surface-subsurface and intermediate-deeper water depth (Methods). The glacial $\delta^{30} \mathrm{Si}_{\text {rad }}$ values range around $-1.1 \%$ and thus are $\sim 2.7 \%$ o lower than the diatom values. During the deglacial transition, surface-subsurface $\delta^{30} \mathrm{Si}_{\text {rad }}$ values in the southern core PS1768-8 increase to $\delta^{30} \mathrm{Si}_{\text {diat }}$ values and remain close to the diatom values during the Holocene (Fig. 4d). Such deglacial convergence of the diatom and radiolarian records is also observed in core PS1778-5, but an offset of $\sim 0.9 \%$ o between $\delta^{30} \mathrm{Si}_{\text {diat }}$ and $\delta^{30} \mathrm{Si}_{\text {rad }}$ persists into the early Holocene (Fig. $4 \mathrm{~h}$ ).

We interpret the glacial offsets between the $\delta^{30} \mathrm{Si}_{\text {diat }}$ and $\delta^{30} \mathrm{Si}_{\text {rad }}$ records as resulting from the presence of a glacial surfacewater stratification separating the diatom and radiolarian habitats at the time of their production (spring-summer). Considering that the $\delta^{18} \mathrm{O}_{\text {diat }}$ records are not indicative of significant freshwater supply, we suggest that the stratification is primarily induced by sea-ice melt during spring, as melting sea ice has no significant effect on the oxygen isotopic composition of surface waters ${ }^{42}$ but largely affects surface ocean salinity and thus the surface water structure even beyond the winter sea-ice edge. The effect of sea-ice melting during spring is assisted by seasonal warming and weakening winds as observed in the modern SO. Assuming that the offsets between the $\delta^{30} \mathrm{Si}_{\text {diat }}$ and $\delta^{30} \mathrm{Si}_{\text {rad }}$ records reflect stratification in the upper water column, they would point to glacial surface waters with increased silicic acid consumption and subsurface and intermediate deepwaters with higher silicic acid availability. The deglacial convergence between the $\delta^{30} \mathrm{Si}_{\text {diat }}$ and $\delta^{30} \mathrm{Si}_{\text {rad }}$ records may point to a deepening of the spring-summer ML depth (MLD), leading to the same Si pool for surface-subsurface-dwelling radiolarians $(>250 \mu \mathrm{m}$ fraction) and surface-dwelling diatoms at site PS1768-8. Considering that this interpretation is strongly based on a radiolarian isotope signal obtained from a nearly monospecific $>250 \mu \mathrm{m}$ fraction, we are confident that the $\delta^{30} \mathrm{Si}_{\text {rad }}$ signal represents environmental change rather than fractionation effects.

Modelling glacial sea ice and MLD variability. To further evaluate the physical changes associated with sea-ice variations, we re-analysed two model simulations with conditions during the Last Glacial Maximum $(\mathrm{LGM})^{23}$ and interglacial periods ${ }^{43}$, respectively, and performed two additional sensitivity experiments to test the impact of a deglacial $\mathrm{CO}_{2}$ rise and a poleward wind field shift in the SO. All model results are based on simulations using the same fully coupled AOGCM ${ }^{23}$. The model configuration includes the atmosphere component ECHAM5 (ref. $44)$ at $\mathrm{T} 31$ resolution $\left(\sim 3.75^{\circ}\right)$ with 19 vertical layers, complemented by a land-surface scheme including dynamical vegetation $(\mathrm{JSBACH})^{45}$. The ocean component MPI-OM ${ }^{46}$, including the dynamics of sea ice formulated using viscousplastic rheology 47 , has an average horizontal resolution of $3^{\circ} \times 1.8^{\circ}$ with 40 uneven vertical layers. The performance of this climate model was evaluated for SO Holocene ${ }^{43}$ and glacial $^{23}$ conditions, showing that the glacial and interglacial (pre-industrial) sea-ice field (Supplementary Fig. 9) and general ocean circulation can be simulated reasonably well, providing a suitable reference to explore the underlying physical mechanism accounting for the proxy records developed in this study. The model has also been applied to analyse glacial millennial-scale variability $^{48}$ and warm climates in the Miocene ${ }^{49}$. For further details of the model and experimental configuration, see Methods and Supplementary Figs 9-11.

By re-analysing model results for the $\mathrm{LGM}^{23}$ from two latitudinal transects (centred at the respective core locations) across the $\mathrm{SO}$ in $10^{\circ}$ longitudinal windows (Fig. 1), we identify strong seasonal changes in sea-ice cover in the area of both core locations (Fig. 5b,c) consistent with the interpretation of a link between vertical stratification changes and seasonal sea-ice variations. These variations result in annual sea-surface salinity and accompanying MLD variations that favour an increase of the MLD during the season of sea ice growth, followed by an MLD decrease when sea ice declines. Hence, the glacial simulation shows a relatively shallow glacial ML during austral springsummer, reaching minimum values of $40-60 \mathrm{~m}$ in the study area (Fig. 5), which can be attributed to the melting of sea ice during this time. Such a pattern would separate the main habitat depth of diatoms from the deeper living radiolarians as suggested by the glacial diatom-radiolarian $\delta^{30} \mathrm{Si}$ offset (Fig. 4d,h). An MLD deepening is simulated for fall-winter seasons, which is promoted by enhanced vertical mixing during sea-ice formation (Fig. 5).

To test the robustness of this interpretation, zonal heterogeneities in sea-ice distribution need to be taken into account. Therefore, we evaluated the seasonal MLD changes for both the exact latitudes of the core locations (Fig. 5, dashed lines) and the latitudes where the physical conditions coincide with the proxy-based LGM WSIC (Fig. 5, solid lines). The respective WSIC amounts on average to $60 \%$ at PS1768-8 and to $41.6 \%$ at PS1778-5 (Supplementary Fig. 6). This approach ties the proxybased information from the sediment cores to physical conditions simulated by the model. Based on this approach, we can estimate that during glacial spring-summer the MLD reached minimum values between 40 and $60 \mathrm{~m}$ at both studied sites and increased during sea-ice formation in fall-winter, reaching a maximum depth of up to $350 \mathrm{~m}$ at the site located in the area of the GWIE (Fig. 5a).

\section{Discussion}

The combination of proxy data and AOGCM modelling implies that the sea surface of the glacial SIZ and the GWIE, at least in the Atlantic sector, was distinctly stratified during austral springsummer with a relatively shallow MLD (40-60 m; Fig. 5). Increased glacial deposition of iron ${ }^{50,51}$ released from the melting winter sea ice transformed the glacial SIZ into a seasonally high productivity region governed by primary producers with low Si:N demand ${ }^{5}$, leading to enhanced utilization of nitrate 3,13 , slightly reduced consumption of silicic acid and low opal export ${ }^{50}$ (Fig. 4f). A similar productivity regime was triggered by iron-fertilization experiments in the modern SO, showing that involved diatoms (for example, Chaetoceros) follow a 'boom-and-bust' life cycle strategy characterized by rapid biomass build-up during favourable growth conditions, succeeded by mass mortality and rapid population decline. Such a productivity regime results in enhanced organic carbon but low biogenic opal export to the deep ocean and thus leads to the decoupling of biogenic carbon and opal export ${ }^{12}$. In contrast to modern conditions, this would 

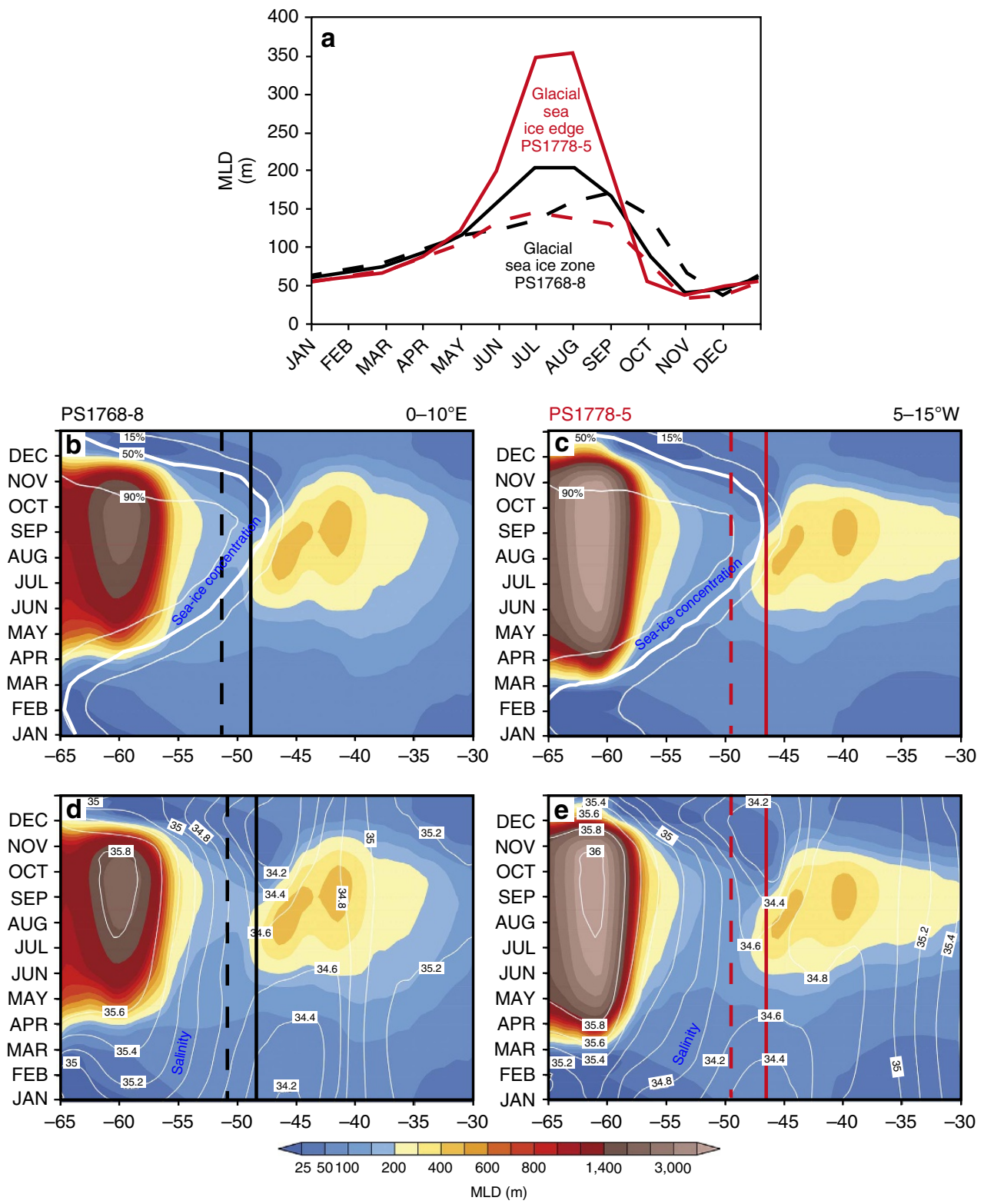

Figure 5 | Modelled monthly averaged MLD, sea-ice concentration and salinity in the Atlantic sector of the Southern Ocean during the LGM.

(a-e) Monthly averaged MLDs for PS1768-8 and PS1778-5 overlaid in $\mathbf{b}$ and $\mathbf{c}$ with sea-ice concentration (\%), and in d and e with sea-surface salinity (psu). Shown are latitudinal transects zonally averaged between 0 and $10^{\circ} \mathrm{E}$ (for PS1768-8), and 5 and $15^{\circ} \mathrm{W}$ (for PS1778-5). Dashed lines indicate the respective changes at the exact latitudinal positions of the cores, whereas the solid lines show the changes at the latitudinal position, where the physical conditions coincide with the reconstructed proxy-based LGM WSIC. The transect zone and core locations are indicated in Fig. 1. The relatively deep glacial MLD at ca. $60-65^{\circ} \mathrm{S}$ in the Weddell Sea (b-e) are mainly attributed to strengthened brine rejection associated with enhanced in-situ sea-ice formation and northward sea-ice export, which are key processes for SO deep water formation during the LGM (for example, see ref. 23).

convert the glacial SIZ, which was enlarged during the glacial ${ }^{34,52}$, into an efficient carbon sink during spring-summer. Authigenic uranium concentrations, a potential proxy for organic carbon deposition, support this view, because they display increased values in sediments deposited in the glacial SIZ ${ }^{50}$.

For the area of the GWIE (PS1778-5), modelling suggests even longer-lasting spring-summer stratification compared with the glacial SIZ (PS1768-8) (Fig. 5). However, in this environment a different productivity-export regime developed. This regime is characterized by the production of thick-shelled diatoms ( $\mathrm{Si}: \mathrm{N}$ ratios $>4$, ref. 53) leading to enhanced silicic acid utilization $\left(\delta^{30} \mathrm{Si}_{\text {diat }}=+1.62 \%\right.$ to $+1.86 \%$ o $)$ at the sea surface and high percentages of biogenic opal in the sediments ${ }^{5,50}$ (Fig. 4h,j). Species involved (for example, Fragilariopsis kerguelensis) ${ }^{5}$ follow a 'persistence' strategy and are hallmarked by enhanced ability to withstand grazing pressure. They are most prominent producers in the modern iron-limited open SO and present efficient silica sinkers $^{12}$ with a major contribution to the modern Antarctic opal belt ${ }^{5}$. Sediment records suggest that this regime extended from the glacial SIZ into the area of the modern Subantarctic Zone as mirrored by increased opal flux and dominant deposition of F. kerguelensis ${ }^{5,50}$.

The northward displacement of the zone of enhanced opal burial (opal belt) together with winter sea-ice expansion ${ }^{50}$ during glacial periods was identified to represent a phenomenon most difficult to explain ${ }^{3}$. Queries concern the northward transfer of required nutrients from the glacial Antarctic Zone, assuming that surface water stratification resulted in reduced nutrient supply 
and almost complete consumption of available nutrients in this zone during the glacial ${ }^{3,13}$. Suggested explanations address increased leakage of silica into the Subantarctic region ${ }^{3,54}$ and northward-shift in wind-driven upwelling ${ }^{13}$. We emphasize a process (nutrient supply by winter mixing) that has been previously rejected ${ }^{13}$. Our modelling suggests that the shallow spring-summer stratification was disrupted by a significant MLD increase during glacial austral winter. The simulations indicate that the winter MLD is more than double the summer MLD in the area of PS1768-8 $(\sim 200 \mathrm{~m})$ and up to $350 \mathrm{~m}$ close to the GWIE (Fig. 5a). Around the GWIE and north of it, thus in the zone of enhanced glacial opal export ${ }^{50}$, modelling indicates even deeper ML conditions during glacial winter (Fig. 5). Such a deep MLD would allow for efficient nutrient refueling of glacial winter surface waters. A deep winter mixing would provide high nutrient (for example, $\mathrm{Si}(\mathrm{OH})_{4}$ ) availability at the onset of spring-summer production when surface water stratification is suggested to develop. A similar winter mixing process between ML, Winter Water and CDW is also suggested to take place in the modern SO (refs 29,30). During spring-summer stratification, nutrient supply to the ML may be accomplished by diapycnal diffusion as described from the modern SO (ref. 55).

Amplification of the nutrient injection into the glacial surface ocean may stem from the presence of a deep reservoir that was more enriched in $\mathrm{Si}(\mathrm{OH})_{4}$ compared with modern conditions. The $\delta^{30} \mathrm{Si}_{\text {diat }}$ values at both studied sites point to similar isotopic compositions of the glacial ML and the modern ML (Fig. 3). However, the glacial radiolarian-derived $\delta^{30} \mathrm{Si}_{\mathrm{Si}(\mathrm{OH}) 4}$ signal that can be related to surface-subsurface conditions (fraction $>250 \mu \mathrm{m})$ is close to modern $\delta^{30} \mathrm{Si}_{\mathrm{Si}(\mathrm{OH}) 4}$ values reported from the nutrient replete Winter Water and CDW in the Atlantic sector south of the Antarctic Polar Front. In contrast to the Holocene, the glacial radiolarian-derived $\delta^{30} \mathrm{Si}_{\mathrm{Si}(\mathrm{OH}) 4}$ values from the fractions $125-250 \mu \mathrm{m}$ and $>125 \mu \mathrm{m}$, which reflect intermediate and deeper water conditions as well, are distinctly lower. These lower values fall in the range of $\delta^{30} \mathrm{Si}_{\mathrm{Si}(\mathrm{OH}) 4}$ values reported from the modern deep Northwest Pacific (approximately $+0.5 \%$ ), which are related to the highest $\mathrm{Si}(\mathrm{OH})_{4}$ concentrations observed in the World Ocean $\left(\sim 160-180 \mu \mathrm{moll}^{-1}\right)^{20}$ (Fig. 3b). Although our estimates still bear uncertainties, our reconstructions using different radiolarian fractionation offsets consistently result in lower glacial $\delta^{30} \mathrm{Si}_{\mathrm{Si}(\mathrm{OH}) 4}$ values and thus higher glacial $\mathrm{Si}(\mathrm{OH})_{4}$ concentrations in $\mathrm{SO}$ intermediate deepwaters compared with the Holocene.

The suggested presence of higher $\mathrm{Si}(\mathrm{OH})_{4}$ concentrations in glacial circumpolar deep waters may be challenged by sponge spicule-based $\delta^{30} \mathrm{Si}$ records from the Scotia Sea, interpreted to indicate that the glacial deep $\mathrm{Si}(\mathrm{OH})_{4}$ concentrations were not different from modern conditions ${ }^{21}$. However, the records exhibit very negative $\delta^{30} \mathrm{Si}$ values $(-3 \%$ to $-3.5 \%$ ) and thus are in a range where the application of this proxy to sponge spicules is prone to larger uncertainties ${ }^{56}$. Another sponge spicule-derived $\delta^{30} \mathrm{Si}$ record from the area straddled by the Subtropical Front (ODP1089, Fig. 1), indicating no significant glacial-interglacial contrast in bottom water $\mathrm{Si}(\mathrm{OH})_{4}$ concentration in the Atlantic sector $^{22}$, is not in conflict with our results. Indeed, this observation allows for approximation of the northern extent of higher $\mathrm{Si}(\mathrm{OH})_{4}$ concentrations trapped in the glacial SO. Presuming a similar relationship between modern and glacial biogenic opal deposition and decline of high silicic acid concentration throughout the water column (Supplementary Fig. 12), the northward displacement of the biogenic opal belt by $\sim 5^{\circ}$ in latitude ${ }^{50}$ would place the glacial silicic acid front in the area between 50 and $45^{\circ} \mathrm{S}$, but not as far north as the area of site ODP1089 (Fig. 1). This is in line with a northward migration of the Subantarctic Front as postulated from the mapping of ${ }^{14} \mathrm{C}$ reservoir ages ${ }^{57}$. Further support comes from the pattern of LGM surface water temperature ${ }^{34}$ and model simulations, indicating a frontal northward displacement by $\sim 5^{\circ}-7^{\circ}$ in latitude from interglacial to glacial conditions (Supplementary Fig. 10).

A glacial SO trapping nutrients more efficiently than at present is consistent with the scenario of an Antarctic deep water body, whose age relative to the atmosphere was more than two times older than during the Holocene, and which was presumably $\mathrm{CO}_{2}$ enriched $^{57}$ and characterized by increased salinity as mirrored by our model ${ }^{23}$ and suggested by proxy data ${ }^{58}$. Possible mechanisms that have an impact on the nutrient trapping may include windgenerated changes of upwelling and downwelling in the SO, sea-ice extent variability and the availability of iron ${ }^{54}$. A glacial northward export of the nutrient $\mathrm{Si}$ (Silicic Acid Leakage Hypothesis) would be in some conflict with a glacial SO nutrient enrichment, but data suggest that enhanced Si leakage was confined to the deglacial period ${ }^{19}$. Indeed, the sponge spiculederived $\delta^{30} \mathrm{Si}$ record from the Subantarctic Atlantic (ODP1089, Fig. 1) indicates a bottom water spillout of the SO reservoir during this time, marked by a distinct $\delta^{30} \mathrm{Si}$ excursion towards more negative values (increased $\mathrm{Si}(\mathrm{OH})_{4}$ concentrations) ${ }^{22}$. Such $\mathrm{Si}(\mathrm{OH})_{4}$ export would support the hypothesis that an expansion of $\mathrm{Si}(\mathrm{OH})_{4}$-enriched Antarctic Bottom Water was the source for maximum opal fluxes (diatom blooms) in the coastal upwelling area off northwest Africa during the last deglaciation ${ }^{59}$.

The glacial-interglacial transition is characterized by successive changes, starting with the retreat of the sea ice that is accompanied by an increase in opal sedimentation between 18,000 and 16,000 years ago (Fig. 4e,f). This is followed by a steep increase in ocean ventilation at about 15,000 years ago ${ }^{58}$ (Fig. 4 b), which marks the rapid intensification in Atlantic thermohaline circulation at the onset of the Bølling ${ }^{60}$. Assuming that the deglacial convergence between our $\delta^{30} \mathrm{Si}_{\text {diat }}$ and $\delta^{30} \mathrm{Si}_{\text {rad }}$ records reflects a deepening of the spring-summer MLD as proposed above, the MLD deepening would coincide with increased biogenic opal rain (Fig. 4d,f). Owing to a data gap in our $>250 \mu \mathrm{m}$ radiolarian record in PS1768-8, we cannot document exactly the onset of the change in surface water structure in the glacial SIZ. However, considering that the available record is closely tied to the retreat of sea ice and increasing deposition of biogenic opal (Fig. $4 \mathrm{~d}-\mathrm{f}$ ), we speculate that the process of MLD deepening was initiated around 18,000 years ago, and that the MLD possibly reached its maximum thickness at around 14,000 years. In core PS1768-8, this is documented by the lowest $\delta^{30} \mathrm{Si}_{\text {diat }}$ values in the studied sediment interval (Fig. 4d). These $\delta^{30} \mathrm{Si}_{\text {diat }}$ minima that are only recorded by surface dwellers (diatoms) during a time of enhanced ventilation and maximum biogenic opal export suggest that the supply of silicic acid exceeded the consumption by diatoms during this time interval. This points to the injection of nutrient-rich deep waters into the euphotic zone ${ }^{5}$, interpreted to result from enhanced wind-driven upwelling governing biogenic opal production and export ${ }^{6}$.

The deglacial MLD deepening leads to conditions that persist in the Holocene (PS1768-8) as recorded by diatom and surfacesubsurface radiolarian $(>250 \mu \mathrm{m}) \delta^{30} \mathrm{Si}$, which can be related to modern ML conditions in the Atlantic sector of the SO (Fig. 3a). The Holocene down-core data are comparable to available $\delta^{30} \mathrm{Si}_{\text {diat }}$ and $\delta^{30} \mathrm{Si}_{\text {rad }}$ data from surface sediments (assumed to reflect modern conditions) in the study area (Fig. $4 \mathrm{~d}, \mathrm{~h}$ ).

It has been postulated that the destratification and enhanced upwelling during the last deglaciation allowed for a $\mathrm{CO}_{2}$ release from the deep SO, providing a direct link to the coinciding increase in atmospheric $\mathrm{CO}_{2}$ (ref. 6). The primary mechanisms proposed to drive the destratification is a southward shift in the Southern Westerlies winds in response to a displacement of the Earth's thermal equator, the Intertropical Convergence Zone ${ }^{6}$. 
Another mode of operation can be derived from our sensitivity experiments applying a prescribed atmospheric $\mathrm{CO}_{2}$ increase from 180 to 240 p.p.m.v. (representing a surrogate for deglacial warming) and a poleward shift of the Southern Westerlies wind belt by $3^{\circ}$ (Supplementary Figs 10 and 11). The sensitivity experiments show that the poleward shift of the Westerlies has a negligible effect on the position of the Antarctic Polar Front and MLD in comparison with the changes induced by the increase in atmospheric $\mathrm{CO}_{2}$ (Supplementary Figs 10 and 11). This suggests that the destratification during the last deglaciation can be primarily attributed to sea-ice margin retreat induced by atmospheric warming and an associated southward shift of the seasonal sea-ice melting zone.

The view that sea ice presents the major player in governing SO glacial surface-water structure and related ocean-atmosphere exchange, nutrient cycling and biological productivity and export regimes entrains major implications to be considered for the estimation of SO effects on the climate system. Quantification of the impact of physical and biological processes in the $\mathrm{SO}$ on the glacial carbon cycle requires consideration of seasonal variability in sea-ice extent and related seasonal and spatial variability in surface ocean mixing rates. Other factors to be taken into account are the development of specific productivity regimes making the SIZ an efficient carbon sink and the area north of the sea-ice edge a region that primarily affects the $\mathrm{Si}$ cycle, and the potential establishment of a nutrient-enriched deep SO reservoir.

\section{Methods}

Stratigraphy. To generate reliable age models for the studied cores, which lack continuous foraminiferal isotope records and carbonate-based $\mathrm{AMS}^{14} \mathrm{C}$ data series, we considered the strategy and stratigraphic data presented in a compilation of last glacial sea-surface temperature and sea-ice records from the Atlantic sector of the $\mathrm{SO}^{38}$. We have revised the correlation of 12 cores including PS1768-8 and PS1778-5 using $53 \mathrm{AMS}^{14} \mathrm{C}$ dates from 8 cores (with $3 \mathrm{AMS}^{14} \mathrm{C}$ dates available from PS1768-8) in addition to intercore correlation based on different parameters. The $\mathrm{AMS}^{14} \mathrm{C}$ dates were converted to calendar years and presented as cal. ka BP $\left(10^{3}\right.$ years before present). Parameters used for intercore correlation include the abundance pattern of the radiolarian Cycladophora davisiana and the diatom E. antarctica, together with foraminiferal oxygen isotope records, if available. Correlations were performed with AnalySeries 2.0 (ref. 61). The age assignment of the radiolarian and diatom abundance pattern was inferred from $\mathrm{AMS}^{14} \mathrm{C}$ dates obtained from 12 cores from the study area ${ }^{38}$. Stratigraphic pointers for both cores (including the $\mathrm{AMS}^{14} \mathrm{C}$ dates from PS1768-8) and their definition are presented in Supplementary Tables 5 and 6 . Although this approach to construct age models for SO records bears uncertainties due to interpolations, especially in (mostly glacial) intervals that could not be dated by continuous ${ }^{14} \mathrm{C}$ dates or $\delta^{18} \mathrm{O}$ data, we are confident that our age model is robust enough to allow for appropriate documentation of the environmental development from the last glacial into the present interglacial. According to our age models, the summer SST and WSIC began to shift towards Holocene values between 18 and $16 \mathrm{cal}$. ka BP (Fig. 4 and Supplementary Figs 7 and 8). This timing fits well with the onset of Southern Hemisphere warming and the start of $\mathrm{CO}_{2}$ release documented in Antarctic ice cores, dated independently of our approach ${ }^{62,63}$. Increase and decline of biogenic opal sedimentation is similar to the pattern recorded from the nearby core TN057-13 (ref. 6). However, in contrast to TN057-13, the biogenic opal, summer SST and WSIC records in our core PS1768-8 display no distinct variations, which can clearly be attributed to short-term climate variability (for example, the Antarctic Cold Reversal) during the last deglacial period. This may be attributed to three- to fourfold higher sedimentation rates at site TN057-13 (ref. 6) compared with site PS1768-8.

Isotopes in biogenic opal. A prerequisite for measuring $\delta^{18} \mathrm{O}$ and $\delta^{30} \mathrm{Si}$ in diatom and radiolarian opal is the careful extraction and separation of sufficient purified material from both microfossil groups (Supplementary Figs 1-4). This is because the different life strategies and depth habitats of the two microfossil groups and different species within these groups, as well as contamination by sponge spicules and non-biogenic components (for example, rock fragments and clay minerals), may affect the isotope signal. For our study we have applied a new method, which allows for the separation of pure diatom and radiolarian fractions from the same sample aliquot. With our technical setup, an average of $2 \mathrm{mg}$ purified diatom or radiolarian opal per sample is needed to obtain combined $\delta^{18} \mathrm{O}$ and $\delta^{30} \mathrm{Si}$ measurements from the same sample aliquot. This represents the lowest amount yet used for such combined measurements in comparison with other measuring techniques ${ }^{64}$. Considering that replicates and triplicates should be measured, as far as sample availability allows, to test the reproducibility of the measurements, the amount of opal to be separated and to be enriched increases accordingly. This precludes in general the separation of radiolarians by picking single radiolarian skeletons, because such a procedure takes an extraordinary expenditure of time. To generate well-established and large sample sets, a routine preparation method has been developed allowing for the removal of non-biogenic components and biogenic carbonate followed by the separation and enrichment of radiolarians and diatoms in specific size fractions.

Sample preparation includes wet-chemical cleaning and extraction of radiolarian and diatoms through different sieving and settling techniques (Supplementary Fig. 1). The samples are first washed with $\mathrm{HCl}$ and $\mathrm{H}_{2} \mathrm{O}_{2}$ to remove carbonates and organic material. Mineral grains are removed through density separations (on average ten density treatments for silica-rich sediments from the SO) using specific sodium polytungstate solutions. The separation of radiolarians from diatoms and sponge spicules is accomplished through several sieving and settling steps combined with ultrasonic treatment. Our tests show that after ultrasonic treatment radiolarians are still intact, whereas diatoms break up and can be removed through sieving. Repetitions of ultrasonic treatment and sieving steps lead to the separation and enrichment of radiolarians and diatoms in different size fractions. For isotope determinations, we use the pure $10-40 \mu \mathrm{m}$ diatom fraction (both cores), the $>250-\mu \mathrm{m}$ and the 125 - to $250-\mu \mathrm{m}$ pure radiolarian fraction for core PS1768-8. As there was not enough material, we could only use one radiolarian fraction $(>125 \mu \mathrm{m})$ for core PS1778-5 and one radiolarian fraction $(>250 \mu \mathrm{m}$ or $>125 \mu \mathrm{m})$ for each surface sediment sample (Supplementary Tables 3 and 7). The smaller size fraction $40-125 \mu \mathrm{m}$ contains radiolarians and diatoms of similar size, which are difficult to separate from each other and thus were not used for isotope measurements. Microscopic slides for determining the species composition of diatoms and radiolarians were prepared after completion of the preparation and separation of the preparation line (Supplementary Fig. 1).

For the combined oxygen and silicon isotope measurements, the cleaned radiolarian and diatom samples were dehydrated at $1,100^{\circ} \mathrm{C}$ by inert gas flow dehydration under a He flow and further reacted to $\mathrm{SiF}_{4}$ and $\mathrm{O}_{2}$ by laser fluorination under $\mathrm{BrF}_{5}$ atmosphere. The liberated oxygen was cleaned of any byproducts and analysed with a PDZ Europa 2020 mass spectrometer according to the method described in refs 65,66 . The ${ }^{18} \mathrm{O} /{ }^{16} \mathrm{O}$ reference ratio of known isotopic composition is measured in analogy to the ${ }^{18} \mathrm{O} /{ }^{16} \mathrm{O}$ sample and the final $\delta^{18} \mathrm{O}$ value was calculated relative to Vienna standard mean ocean water. For silicon isotope measurements, the separated and cleaned $\mathrm{SiF}_{4}$ gas was directed into glass vials and measured separately with a Finnigan MAT 252 mass spectrometer and measured against the ${ }^{30} \mathrm{Si} /{ }^{28} \mathrm{Si}$ reference ratio of a $\mathrm{SiF}_{4}$ gas of known isotopic composition $^{18}$. The final $\delta^{30} \mathrm{Si}$ value was calculated relative to NBS-28. To test the reproducibility of the measurements at least, replicates and triplicates were measured on all samples with sufficient amount of material (Supplementary Tables 3 and 7-12). The analytical precision of silicon isotope measurements was better than $\pm 0.12 \%$ o $\left(\delta^{30} \mathrm{Si} ; 1 \sigma\right)$ for all used working standard materials ${ }^{18}$. The overall precision for all working standards used for oxygen isotope measurements lies between $\pm 0.2 \%$ and $0.3 \%$ o $(1 \sigma)$ (refs 40,66 ).

Purity of samples prepared for isotope measurements. In general, contamination of biogenic opal samples by minerals (for example, quartz, feldspar, micas, clay minerals, rock fragments and volcanic tephra) can bias, especially the $\delta^{18} \mathrm{O}$ signal towards lower values ${ }^{17,40}$, a pattern that may lead to misinterpretation of the isotope results. Considering that the contaminants may be silicates that are difficult to remove with the generally applied cleaning methods, the purity of the samples cleaned for isotope measurements needs to be tested. We can document that the cleaning procedure applied in our study leads to very well-purified diatom and radiolarian samples. Our testing of samples from core PS1768-8 using inductively coupled plasma optical emission spectrometry and energy-dispersive $\mathrm{X}$-ray spectrometry indicates (1) a high degree of purification with the near absence of elemental compositions, indicating non-biogenic components, and (2) $\mathrm{SiO}_{2}$ contents ranging between $98.5 \%$ and $99.5 \%$ (inductively coupled plasma optical emission spectrometry), and $97.9 \%$ and $99.8 \%$ (energy-dispersive X-ray spectrometry) (Supplementary Table 1).

Effect of dissolution on the isotope signals. Only few studies concern the potential impact of diagenesis on the opal isotope signal, which come to opposing results concerning the effect of dissolution on the $\delta^{30} \mathrm{Si}$ signal ${ }^{19}$. The diatoms extracted in this study are mainly composed of heavily silicified diatoms such as E. antarctica and T. lentiginosa, and are not affected by dissolution (Supplementary Fig. 3). The (rare) occurrence of very well-preserved thinly silicified diatoms (for example, Rhizosolenia sp.) confirms the excellent preservation of the diatom assemblage (Supplementary Fig. 3). This also concerns the radiolarian fractions, which are mainly composed of large and heavily silicified specimens, which are well preserved, although they were treated in the ultrasonic bath for several hours (Supplementary Fig. 4).

Species composition of diatom and radiolarian fractions. For the isotopic measurements, we used a pure diatom fraction $(10-40 \mu \mathrm{m})$ for the representation of surface-water conditions. This fraction mainly consists of the species 
E. antarctica (glacial indicator) and T. lentiginosa making up between $70 \%$ and $98 \%$, and $78 \%$ and $97 \%$ of the species composition in the extracted diatom fractions of PS1768-8 and PS1778-5, respectively (Supplementary Fig. 5). The amount of these species in the original diatom assemblages is on average only between $20 \%$ and $29 \%$. The difference in diatom species composition between the original sample and the extracted fraction results from our techniques for purification and extraction of a specific size class allowing for the generation of samples containing the least possible number of species. The shift from E. antarctica-dominated fractions to fractions with increased T. lentiginosa abundances occurs abruptly between three sample depths and is unrelated to the more gradual change in isotope signal across the glacial-interglacial shift (Supplementary Fig. 5). Smallsized sea-ice-related diatoms (for example, Fragilariopsis curta) that are not or only rarely included in the $10-40 \mu \mathrm{m}$ diatom fraction do not affect the isotope signal.

For the isotopic measurements on radiolarians, we used three radiolarian fractions to document surface-subsurface and intermediate deepwater conditions. In core PS1768-8, we measured the $>250 \mu \mathrm{m}$ fraction, which is composed of two radiolarian species: A. antarctica, which accounts for $>90 \%$ of radiolarians in this fraction, and S. glacialis (adult forms), which ranges between $1 \%$ and $10 \%$ in this fraction. As different radiolarian species live in different water depths, we used data from a plankton study in the Atlantic sector of the SO (ref. 25), to get information about the depth habitat of radiolarians in the upper $1,000 \mathrm{~m}$ of the water column (Supplementary Fig. 13 and Supplementary Table 2). Both species occur in the upper $200-400 \mathrm{~m}$ with $\mathrm{S}$. glacialis predominantly occurring in the upper $100 \mathrm{~m}$ and A. antarctica in the upper $300-400 \mathrm{~m}$. As there was not enough material to separate the $>250-\mu \mathrm{m}$ fraction from core PS1778-5, we used here the $>125-\mu \mathrm{m}$ fraction for radiolarian isotope measurements. This fraction is also dominantly composed of the two species A. antarctica and S. glacialis, but in contrast to the $>250-\mu \mathrm{m}$ fraction from core PS1768-8 the $>125-\mu \mathrm{m}$ fraction also contains deeper living species (for example, Spongopyle osculosa, Spongogurus pylomaticus and Cromyecheinus antarctica) that occur in water depths $>400 \mathrm{~m}$ (ref. 25). As the $\delta^{30} \mathrm{Si}_{\text {rad }}$ values of the $>125-\mu \mathrm{m}$ fraction exhibit distinctly lower values (glacial average $-1.06 \%$ ) than the $\delta^{30} \mathrm{Si}_{\text {rad }}$ values from the $>250-\mu \mathrm{m}$ fraction from core PS1768-8 (average glacial values $+0.54 \%$ ), we segregated the $125-$ to $250-\mu \mathrm{m}$ fraction from core PS1768-8 to get more information about this latitudinal difference in the $\delta^{30} \mathrm{Si}$ signature. The $\delta^{30} \mathrm{Si}_{\mathrm{rad}}$ measurements from this fraction show distinctly lower values (glacial average $-0.67 \%$ ) than the $\delta^{30} \mathrm{Si}_{\text {rad }}$ values from the $>250-\mu \mathrm{m}$ fraction. The fraction $125-250 \mu \mathrm{m}$ also includes deeper dwelling radiolarians similar as in the $>125-\mu \mathrm{m}$ fraction from core PS1778-5. This suggests that the presence of deeper dwelling radiolarians shifts the $\delta^{30} \mathrm{Si}$ signal to lower values. C. davisiana, a species typical for glacial assemblages, is not included to the fractions $>125 \mu \mathrm{m}$ because of its small size, which impedes a potential impact of this species on glacial results.

\section{Estimation of $\delta^{30} \mathrm{Si}_{\mathrm{Si}(\mathrm{OH}) 4}$ and $\mathrm{Si}(\mathrm{OH})_{4}$ concentrations. The estimation of}

Holocene and glacial silicic acid changes were carried out as follows:

1 . The average $\delta^{30} \mathrm{Si}$ values of the diatom $(10-40 \mu \mathrm{m})$ and radiolarian fractions ( $>250,125-250$ and $>125 \mu \mathrm{m}$ ) for the Holocene (until $12 \mathrm{cal}$. ka BP) and the last glacial period ( $\sim 19-29$ cal. ka BP) were calculated (Supplementary Table 4$)$.

2. Based on the average diatom and radiolarian $\delta^{30} \mathrm{Si}$ values, the $\delta^{30} \mathrm{Si}_{\mathrm{Si}(\mathrm{OH}) 4}$ values for the Holocene and last glacial period were calculated using the formula:

$$
\begin{aligned}
& \Delta \delta^{30} \mathrm{Si}=\delta^{30} \mathrm{Si}_{\mathrm{BSi}}-\delta^{30} \mathrm{Si}_{\mathrm{Si}(\mathrm{OH}) 4} \\
& \delta^{30} \mathrm{Si}_{\mathrm{Si}(\mathrm{OH}) 4}=\delta^{30} \mathrm{Si}_{\mathrm{BSi}}-\Delta \delta^{30} \mathrm{Si}
\end{aligned}
$$

where $\delta^{30} \mathrm{Si}_{\mathrm{BSi}}$ is the silicon isotope composition of biogenic silica (diatoms or radiolarians), $\delta^{30} \mathrm{Si}_{\mathrm{Si}(\mathrm{OH}) 4}$ is the silicon isotope composition of the input sea water (Supplementary Table 4 ) and $\Delta \delta^{30} \mathrm{Si}$ is the fractionation offset. The calculations were performed using different $\Delta \delta^{30} \mathrm{Si}$ values: $\Delta \delta^{30} \mathrm{Si}_{\text {diat }}=-1.1 \%$ (ref. 24), $\Delta \delta^{30} \mathrm{Si}_{\text {rad }}=-0.8 \%$ (average $\Delta \delta^{30} \mathrm{Si}_{\text {rad }}$ this study, Supplementary Table 4 ), $\Delta \delta^{30} \mathrm{Si}_{\text {rad }}=-1.2 \%$ (average $\Delta \delta^{30} \mathrm{Si}_{\text {rad }}$ of this study and ref. 32 ),

$\Delta \delta^{30} \mathrm{Si}_{\text {rad }}=-1.5 \%$ (average $\Delta \delta^{30} \mathrm{Si}_{\text {rad }}$ of ref. 32 ).

3. The reconstructed $\delta^{30} \mathrm{Si}_{\mathrm{Si}(\mathrm{OH}) 4}$ values were related to $\delta^{30} \mathrm{Si}_{\mathrm{Si}(\mathrm{OH}) 4}$ values and $\mathrm{Si}(\mathrm{OH})_{4}$ concentrations from different water masses reported from modern water-column studies ${ }^{20,28,29}$. We note that our reconstructed ${ }^{30} \mathrm{Si}_{\mathrm{Si}(\mathrm{OH}) 4}$ values reflect a rather broad range in $\mathrm{Si}(\mathrm{OH})_{4}$ concentrations (Fig. 3 and Supplementary Table 4). In spite of this large range in variability, our calculated $\delta^{30} \mathrm{Si}_{\mathrm{Si}}(\mathrm{OH}) 4$ values for the diatoms and different radiolarian fractions are in the range of $\delta^{30} \mathrm{Si}_{\mathrm{Si}(\mathrm{OH}) 4}$ values of specific water masses and reflect their range in $\mathrm{Si}(\mathrm{OH})_{4}$ concentrations ${ }^{20,28,29}$ (Fig. 3 and Supplementary Table 4).

Reconstruction of WSIC. WSIC (\%) was estimated from the diatom assemblage composition preserved in the sediment records using the transfer function technique. For our study we selected the estimations obtained with the Imbrie and Kipp transfer function method using a setup with 172 reference sites, 28 diatom taxa/taxa groups, logarithmic-transformed diatom data, quadratic regression and a three-factor model with a root mean square error of prediction of $7.3 \%$ (ref. 35). Similar patterns of sea-ice concentration were also obtained with three other transfer function techniques, all showing the onset of sea-ice retreat after the last glacial period at around 18,000 years ago ${ }^{35}$. Although the diatom signal used for the estimate of WSIC is based on a signal produced during the diatom springsummer bloom, experimental (sediment trap) data and statistical test show that this signal reflects the occurrence probability of winter sea ice, which is well correlated with the WSIC at a given site (ref. 35 and references included therein).

Model setup and experimental design. For our simulations we use the experimental settings of the LGMW simulations in ref. 23, which is integrated for 4,000 years from a cold ocean state, to evaluate MLD characteristics under LGM (21 ka) and present-day conditions, as well as for the sensitivity experiments. The thermodynamics of sea ice relate changes in sea-ice thickness to a balance of radiant, turbulent and oceanic heat fluxes. The effect of snow accumulation is taken into account, along with snow-ice transformation when the snow-ice interface sinks below the sea level because of snow loading. The impact of ice growth and ice melting is included in the model, assuming a sea-ice salinity of $5 \mathrm{PSU}^{46}$. In experiment WIND, the implementation of the poleward wind field shift ( $3^{\circ}$ southwards) of the Westerlies in the SO (experiment WIND, Supplementary Figs 10 and 11) has been performed in analogy to ref. 43. In experiment $\mathrm{CO} 2$, a deglacial $\mathrm{CO}_{2}$ increase from 180 to 240 p.p.m.v. has been applied. Both experiments have been integrated for 600 years. All figures show climatological mean characteristics averaged over a period of 100 years at the end of each simulation.

\section{References}

1. Petit, J. R. et al. Climate and atmospheric history of the past 420,000 years from the Vostok ice core, Antarctica. Nature 399, 429-436 (1999).

2. Archer, D. E., Winguth, A., Lea, D. \& Mahowald, N. What caused the glacial/interglacial atmospheric $\mathrm{pCO}_{2}$ cycles? Rev. Geophys. 38, 159-186 (2000).

3. Sigman, D. M, Hain, M. P \& Haug, G. H. The polar ocean and glacial cycles in atmospheric $\mathrm{CO}_{2}$ concentration. Nature 466, 47-55 (2010).

4. Parrenin, F. et al. Synchronous change of atmospheric $\mathrm{CO}_{2}$ and Antarctic temperature during the last deglacial warming. Science 339, 1060-1063 (2013).

5. Abelmann, A., Gersonde, R., Cortese, G., Kuhn, G. \& Smetacek, V. Extensive phytoplankton blooms in the Atlantic Sector of the glacial Southern Ocean. Paleoceanography 21, PA1013, doi:10.1029/2005PA001199 (2006).

6. Anderson, R. F. et al. Wind-driven upwelling in the Southern Ocean and the deglacial rise in atmospheric $\mathrm{CO}_{2}$. Science 323, 1443-1448 (2009).

7. Bouttes, N. et al. Impact of oceanic processes on the carbon cycle during the last termination. Clim. Past 8, 149-170 (2012).

8. Ragueneau, O. et al. A review of the Si cycle in the modern ocean: recent progress and missing gaps in the application of biogenic opal as a paleoproductivity proxy. Global Planet. Change 26, 317-365 (2000).

9. Stephens, B. B. \& Keeling, R. F. The influence of Antarctic sea ice on glacial-inter- glacial $\mathrm{CO}_{2}$ variations. Nature 404, 171-174 (2000).

10. Kurahashi-Nakamura, T., Abe-Ouchi, A., Yamanaka, Y. \& Misumi, K Compound effects of Antarctic sea ice on atmospheric $p \mathrm{CO} 2$ change during glacial-interglacial cycle. Geophys. Res. Lett. 34, L20708, doi:10.1029/ 2007GL030898 (2007).

11. Sun, X. \& Matsumoto, K. Effects of sea ice on atmospheric pCO2: A revised view and implications for glacial and future climates. J. Geophys. Res. 115, G02015 (2010).

12. Assmy, P. et al. Thick-shelled, grazer-protected diatoms decouple ocean carbon and silicon cycles in the iron-limited Antarctic Circum Polar Current. PNAS 110, 20633-20638 (2013).

13. Robinson, R. S. \& Sigman, D. M. Nitrogen isotopic evidence for a poleward decrease in surface nitrate within the ice age Antarctic. Quat. Sci. Rev. 27, 1076-1090 (2008).

14. Shemesh, A., Burckle, L. H. \& Hays, J. D. Late Pleistocene oxygen isotope records of biogenic silica from the Atlantic sector of the Southern Ocean Paleoceanography 10, 179-196 (1995).

15. Shemesh, A. et al. Sequence of events during the last deglaciation in Southern Ocean sediments and Antarctic ice cores. Paleoceanography 17, 599-605 (2002).

16. Pike, J., Swann, G. E. A., Leng, M. J. \& Snelling, A. M. Glacial discharge along the West Antarctic Peninsula during the Holocene. Nat. Geosci. 6, 199-202 (2013).

17. Swann, G. E. A. \& Leng, M. J. A review of diatom $\delta^{18} \mathrm{O}$ in palaeoceanography. Quat. Sci. Rev. 28, 384-398 (2009).

18. Maier, E. et al. Combined oxygen and silicon isotope analysis of diatom silica from a deglacial subarctic Pacific record. J. Quat. Sci. 28, 571-581 (2013).

19. Hendry, K. R. \& Brzezinski, M. A. Using silicon isotopes to understand the role oft the Southern Ocean in modern and ancient biogeochemistry and climate. Quat. Sci. Rev. 89, 13-26 (2014).

20. Reynolds, B. C., Frank, M. \& Halliday, A. N. Silicon isotope fractionation during nutrient utilization in the North Pacific. Earth Planet. Sci. Lett. 244 431-443 (2006)

21. Hendry, K. R., Georg, R. B., Rickaby, R. E. M., Robinson, L. F. \& Halliday, A. N. Deep ocean nutrients during the Last Glacial Maximum deduced from sponge silicon isotopic compositions. Earth Planet. Sci. Lett. 292, 290-300 (2010). 
22. Ellwood, M. J., Wille, M. \& Maher, W. Glacial silicic acid concentrations in the Southern Ocean. Science 330, 1088-1091 (2010).

23. Zhang, X., Lohmann, G., Knorr, G. \& Xu, X. Different ocean states and transient characteristics in Last Glacial Maximum simulations and implications for deglaciation. Clim. Past 9, 2319-2333 (2013).

24. De la Rocha, C. L., Brzezinski, M. A. \& DeNiro, M. J. Fractionation of silicon isotopes by marine diatoms during biogenic silica formation. Geochim. Cosmochim. Acta 61, 5051-5056 (1997).

25. Abelmann, A. \& Gowing, M. M. Spatial distribution pattern of living polycystine radiolarian taxa - baseline study for paleoenvironmental reconstructions in the Southern Ocean (Atlantic sector). Marine Micropaleontol. 30, 3-28 (1997).

26. Abelmann, A. \& Gersonde, R. Biosiliceous particle flux in the Southern Ocean. Marine Chem. 35, 503-536 (1991).

27. Varela, D. E., Pride, C. J. \& Brzezinski, M. A. Biological fractionation of silicon isotopes in Southern Ocean surface waters. Glob. Biogeochem. Cycles 18, GB1047 (2004).

28. Cardinal, D et al. Relevance of silicon isotopes to Si-nutrient utilization and Si-source assessment in Antarctic waters. Glob. Biogeochem. Cycles 19, doi:10.1029/2004GB002364 (2005)

29. Fripiat, F. et al. Silicon pool dynamics and biogenic silica export in the Southern Ocean inferred from Si-isotopes. Ocean Sci. 7, 533-547 (2011).

30. Egan, K. et al. Diatom silicon isotopes as a proxy for silicic acid utilisation: a Southern Ocean core top calibration. Geochim. Cosmochim. Acta 96, 174-192 (2012).

31. Krabberød, A. K. et al. Radiolaria divided into Polycystina and Spasmaria in combined 18S and 28S rDNA Phylogeny. PLoS ONE 6, 23526 (2011).

32. Hendry, K. R. et al. Silicon isotopes indicate enhanced carbon export efficiency in the North Atlantic during deglaciation. Nat. Commun. 5, 3107 (2014).

33. Garcia, H. E. et al. World Ocean Atlas 2009. NOAA Atlas NESDIS 4, 398 (2010).

34. Gersonde, R., Crosta, X., Abelmann, A. \& Armand, L. Sea-surface temperature and sea ice distribution of the Southern Ocean at the EPILOG last Glacial Maximum - a circum-Antarctic review based on siliceous microfossil records. Quat. Sci. Rev. 24, 869-896 (2005).

35. Esper, O. \& Gersonde, R. New tools for the reconstruction of Pleistocene Antarctic sea ice. Palaeogeogr. Climatol. Ecol. 399, 260-283 (2014).

36. Reynolds, R. W. et al. An improved in situ and satellite SST analysis for climate. J. Clim. 15, 1609-1625 (2002).

37. Campbell, W. J. et al. Variations of mesoscale and large-scale sea ice morphology in the 1984 Marginal Ice Zone Experiment as observed by microwave remote sensing. J. Geophys. Res. 92, 6805-6824 (1987).

38. Gersonde, R. et al. Last Glacial sea-surface.temperatures and sea-ice extent in the Southern Ocean (Atlantic-Indian sector) - A multiproxy approach. Paleoceanography 18, doi:10.1029/2002PA000809 (2003).

39. Nielsen, S. H. et al. Origin and significance of ice-rafted detritus in the Atlantic sector of the Southern Ocean. Geochem. Geophys. Geosyst. 8, Q12005 (2007).

40. Chapligin, B. et al. Assessment of purification and contamination correction methods for analysing the oxygen isotope composition from biogenic silica. Chem. Geol. 300-301, 185-199 (2012).

41. De La Rocha, C. L., Brzezinski, M. A., DeNiro, M. J. \& Shemesh, A Silicon-isotope composition of diatoms as indicator of past oceanic change. Nature 395, 680-683 (1998).

42. Craig, H. \& Gordon, L. I. in Stable Isotopes in Oceanographic Studies and Paleotemperatures (ed. Tongiorgi, E.) 9-130 (Consiglio Nazionale della Ricerche Laboratorio di Geologia Nucleare, 1965).

43. Wei, W., Lohmann, G. \& Dima, M. Distinct modes of internal variability in the Global Meridional Overturning Circulation associated to the Southern Hemisphere westerly winds. J. Phys. Oceanogr. 42, 785-801 (2012).

44. Roeckner, E. et al. Sensitivity of simulated climate to horizontal and vertical resolution in the ECHAM5 Atmosphere Model. J. Climate 19, 3771-3791 (2006).

45. Raddatz, T. et al. Will the tropical land biosphere dominate the climate-carbon cycle feedback during the twenty first century? Clim. Dyn. 29, 565-574 (2007).

46. Marsland, S. J., Haak, H., Jungclaus, J. H., Latif, M. \& Röske, F. The MaxPlanck-Institute global ocean/sea ice model with orthogonal curvilinear coordinates. Ocean Modell. 5, 91-127 (2003).

47. Hibler, W. D. A dynamic thermodynamic sea ice model. J. Phys. Oceanogr. 9, 815-846 (1979).

48. Zhang, X., Lohmann, G., Knorr, G. \& Purcell, C. Abrupt glacial climate shifts controlled by ice sheet changes. Nature 512, 290-294 (2014).

49. Knorr, G. \& Lohmann, G. Climate warming during Antarctic ice sheet expansion at the Middle Miocene transition. Nat. Geosci. 7, 376-381 (2014).

50. Frank, M. et al. Similar glacial and interglacial export bioproductivity in the Atlantic sector of the Southern Ocean: multiproxy evidence and implications for glacial atmospheric $\mathrm{CO}_{2}$. Paleoceanography 15, 642-658 (2000).
51. Kohfeld, K. E. et al. Southern Hemisphere westerly wind changes during the last glacial maximum: Paleo-data synthesis. Quat. Sci. Rev. 68, 76-95 (2013).

52. Collins, L. G., Pike, J., Allen, C. \& Hodgson, D. A. High-resolution reconstruction of southwest Atlantic sea-ice and its role in the carbon cycle during marine isotope stages 3 and 2. Paleoceanography 27, PA3217 (2012).

53. Hoffmann, L. J., Peeken, I. \& Lochte, K. Effects of iron on the elemental stoichiometry during EIFEX and in the diatoms Fragilariopsis kerguelensis and Chaetoceros dichaeta. Biogeosciences 4, 569-579 (2007).

54. Matsumoto, K., Chase, Z. \& Kohfeld, K. Different mechansims of silicic acid leakage and their biogeochemical consequences. Paleoceanography 29, 238-254 (2014).

55. Law, C. S., Abraham, E. R., Watson, A. J. \& Liddicoat, M. I. Vertical eddy diffusion and nutrient supply to the surface mixed layer of the Antarctic Circumpolar Current. J. Geophys. Res. 108, 3272 (2003).

56. Wille, M. et al. Silicon isotopic fractionation in marine sponges: a new model for understanding silicon isotopic fractionation in sponges. Earth Planet. Sci. Lett. 292, 281-289 (2010).

57. Skinner, L. C., Fallon, S., Waelbroeck, C., Michel, E. \& Barker, S. Ventilation of the deep Southern Ocean and deglacial $\mathrm{CO}_{2}$ rise. Science 328, 1147-1151 (2010).

58. Adkins, J. K., McIntyre, K. \& Schrag, D. P. The salinity, temperature, and $\delta^{18} \mathrm{O}$ of the glacial deep ocean. Science 298, 1769-1773 (2002).

59. Meckler, A. N. et al. Deglacial pulses of deep-ocean silicate into the subtropical North Atlantic ocean. Nature 495, 495-499 (2013).

60. Knorr, G. \& Lohmann, G. Rapid transition in the Atlantic thermohaline circulation triggered by global warming and meltwater during the last deglaciation. Geochem. Geophys. Geosyst. 8, doi: 10.1029/2007GC001604 (2007).

61. Paillard, D., Labeyrie, L. \& Yiou, P. Macintosh program performs time-series analysis. Eos Trans. AGU 77, 379 (1996).

62. Veres, D. et al. The Antarctic ice core chronology (AICC2012): an optimized multi-parameter and multi-site dating approach for the last 120 thousand years. Clim. Past 9, 1733-1748 (2013).

63. Marcott, S. A. et al. Centennial-scale changes in the global carbon cycle during the last glaciation. Nature 514, 616-619 (2014)

64. Leng, M. J. \& Sloane, H. J. Combined oxygen and silicon isotope analysis of biogenic silica. J. Quat. Sci. 23, 313-319 (2008).

65. Chapligin, B. et al. A high-performance, safer and semiautomated approach for the $\delta^{18} \mathrm{O}$ analysis of diatom silica and new methods for removing exchangeable oxygen. Rapid Comm. Mass Spectrom. 24, 2655-2664 (2010).

66. Chapligin, B. et al. Inter-laboratory comparison of oxygen isotope compositions from biogenic silica. Geochim. Cosmochim. Acta 75, 7242-7256 (2011).

67. Comiso, J. C. in Sea Ice, an Introduction to its Physics, Chemistry, Biology and Geology (eds Thomas, D. N. \& Diekmann, G. S.) 112-142 (Blackwell, 2003)

68. Orsi, A. H., Whitworth, III T. \& Nowlin, jr W. D. On the meridional extend and fronts of the Antarctic Circumpolar Current. Deep Sea Res. I 42, 641-673 (1995).

69. Hendry, K. R. \& Robinson, L. F. The relationship between silicon isotope fractionation in sponges and silicic acid concentration: Modern and core-top studies of biogenic opal. Geochim. Cosmochim. Acta 81, 1-12 (2012).

70. EPICA Community Members. One-to-one coupling of glacial climate variability in Greenland and Antarctica. Nature 444, 195-198 (2006).

\section{Acknowledgements}

We acknowledge Martin Frank for re-estimating the rain rates according to the revised age model. We are grateful to James Collins for his assistance to revise our English. We also thank Ute Bock, Ulrike Böttjer, Ruth Cordelair and Birgit Glückselig for technical support. Financial support for this work was provided by the Deutsche Forschungsgemeinschaft (DFG), AWI Helmholtz-Zentrum für Polar- und Meeresforschung and MARUM Center of Marine Environmental Sciences, University of Bremen. Funding by the 'Helmholtz Climate Initiative REKLIM' (Regional Climate Change), a joint research project of the Helmholtz Association of German Research Centres (HGF), is gratefully acknowledged (G.K.).

\section{Author contributions}

A.A., R.G. and G.K. designed the study. A.A. wrote the manuscript with significant contributions of R.G. and G.K. A.A., B.C., E.M., H.M. and H.F. performed the $\delta^{18} \mathrm{O}$ and $\delta^{30} \mathrm{Si}$ analyses on diatoms and radiolarians. R.G. and O.E. provided sea-ice concentration and surface water temperature estimates. X.Z. conducted the model simulations. All authors contributed to data interpretation and the preparation of the final manuscript.

\section{Additional information}

Supplementary Information accompanies this paper at http://www.nature.com/ naturecommunications 
Competing financial interests: The authors declare no competing financial interests.

Reprints and permission information is available online at http://npg.nature.com/ reprintsandpermissions/

How to cite this article: Abelmann, A. et al. The seasonal sea-ice zone in the glacial

Southern Ocean as a carbon sink. Nat. Commun. 6:8136 doi: 10.1038/ncomms9136 (2015). (c) (i) This work is licensed under a Creative Commons Attribution 4.0 International License. The images or other third party material in this article are included in the article's Creative Commons license, unless indicated otherwise in the credit line; if the material is not included under the Creative Commons license, users will need to obtain permission from the license holder to reproduce the material. To view a copy of this license, visit http://creativecommons.org/licenses/by/4.0/ 


\section{Corrigendum: The seasonal sea-ice zone in the glacial Southern Ocean as a carbon sink}

Andrea Abelmann, Rainer Gersonde, Gregor Knorr, Xu Zhang, Bernhard Chapligin, Edith Maier, Oliver Esper, Hans Friedrichsen, Gerrit Lohmann, Hanno Meyer \& Ralf Tiedemann

Nature Communications 6:8136 doi: 10.1038/ncomms9136 (2015); Published 18 Sep 2015; Updated 15 Jun 2016

The original version of this Article failed to fully credit the use of the Ocean Data View software in figure 1 and supplementary figure 12, which appears below:

Schlitzer, R., Ocean Data View, http://odv.awi.de, 2016.

This work is licensed under a Creative Commons Attribution 4.0 International License. The images or other third party material in this article are included in the article's Creative Commons license, unless indicated otherwise in the credit line; if the material is not included under the Creative Commons license, users will need to obtain permission from the license holder to reproduce the material. To view a copy of this license, visit http://creativecommons.org/licenses/by/4.0/ 